\title{
A search for photometric variability in magnetic chemically peculiar stars using ASAS-3 data
}

\author{
K. Bernhard ${ }^{1,2}$, S. Hümmerich ${ }^{1,2}$, S. Otero ${ }^{2,3}$, and E. Paunzen ${ }^{4}$ \\ 1 Bundesdeutsche Arbeitsgemeinschaft für Veränderliche Sterne e.V. (BAV), 12169 Berlin, Germany \\ e-mail: klaus . bernhard@liwest . at, ernham@rz-online.de \\ 2 American Association of Variable Star Observers (AAVSO), Cambridge, MA 02138, USA \\ 3 Buenos Aires, Argentina \\ ${ }^{4}$ Department of Theoretical Physics and Astrophysics, Masaryk University, Kotlářská 2, 61137 Brno, Czech Republic
}

Received 28 April 2015 / Accepted 4 June 2015

ABSTRACT

\begin{abstract}
Context. The (magnetic) chemically peculiar (CP) stars of the upper main sequence are well-suited laboratories for investigating the influence of magnetic fields on the stellar surface because they produce abundance inhomogeneities (spots), which results in photometric variability that is explained in terms of the oblique rotator model. CP stars exhibiting this phenomenon are normally classified as $\alpha^{2}$ Canum Venaticorum (ACV) variables. It is important to increase the sample of known rotational periods among CP stars by discovering new ACV variables. An increased sample size will contribute to the understanding of the CP stars' evolution in time. Aims. We aim at discovering new ACV variables in the public data of the third phase of the All Sky Automated Survey (ASAS-3). Furthermore, by analysis of the available photometric data, we intend to derive rotational periods of the stars.

Methods. The ASAS-3 data were cross-correlated with the Catalogue of Ap, HgMn, and Am stars in order to analyse the light curves of bona fide $\mathrm{CP}$ and related stars. The light curves were downloaded and cleaned of outliers and data points with a flag indicating bad quality. Promising candidates showing a larger scatter than observed for constant stars in the corresponding magnitude range were searched for periodic signals using a standard Fourier technique. Objects exhibiting periodic signals well above the noise level were considered and visually inspected, whereas borderline cases were rejected.

Results. In total, we found 323 variables, from which 246 are reported here for the first time, and 77 were probably wrongly classified before. The observed variability pattern of most stars is in accordance with an ACV classification. For some cases, it is difficult to distinguish between the light curves of double-waved ACVs and the variability induced by orbital motion (ellipsoidal variables/eclipsing variables), especially for objects exhibiting very small amplitudes and/or significant scatter in their light curves. Thus, some eclipsing or rotating ellipsoidal variables might be present. However, we are confident that the given periods are the correct ones. There seems to be a possible weak correlation between the rotational period and colour, in the sense that cooler magnetic CP stars rotate more slowly. However, this correlation seems to disappear when correcting for the interstellar reddening.

Conclusions. The next steps have to include a compilation of all available rotational periods from the literature and a detailed investigation of the astrophysical parameters of these stars. This includes a determination of the individual masses, luminosities, ages, and inclination angles. However, this information cannot be straightforwardly determined from photometric data alone.
\end{abstract}

Key words. binaries: eclipsing - stars: chemically peculiar - stars: variables: general - techniques: photometric

\section{Introduction}

Chemically peculiar (CP) stars are upper main sequence objects (spectral types early B to early F) whose spectra are characterized by abnormally strong (or weak) absorption lines that indicate peculiar surface elemental abundances. The observed chemical peculiarities are thought to arise from the diffusion of chemical elements due to the competition between radiative pressure and gravitational settling (Richer et al. 2000; Turcotte 2003). CP stars constitute about $10 \%$ of all upper main sequence stars and are commonly subdivided into four classes (Preston 1974): metallic line (or Am) stars (CP1), magnetic Ap stars (CP2), HgMn stars (CP3), and He-weak stars (CP4).

The CP2 or Ap stars, which are the subject of the present investigation, are notorious for exhibiting strong, globally organized magnetic fields of up to several tens of kiloGauss (Kochukhov 2011). Their atmospheres are enriched in elements such as $\mathrm{Si}, \mathrm{Cr}, \mathrm{Sr}$, or Eu and usually present surface abundance patches or spots (Michaud et al. 1981; Kochukhov \& Wade 2010;
Krtička et al. 2013), leading to photometric variability, which is considered to be caused by rotational modulation and explained in terms of the oblique rotator model (Stibbs 1950).

As a result, the observed photometric period is the rotational period of the star. Generally, CP1 stars are not expected to show rotational light variability; in relation to $\mathrm{CP} 3$ stars, this is still a matter of debate (Paunzen et al. 2013; Morel et al. 2014). Interestingly, in a recent study using ultra-precise Kepler photometry, Balona et al. (2015) have found that most of the investigated Am stars exhibit light curves indicative of rotational modulation due to star spots. With an amplitude of up to $200 \mathrm{ppm}$, this kind of variability is reserved for high-precision (space) photometry, though. Photometrically variable CP2 stars are also designated as $\alpha^{2}$ Canum Venaticorum (ACV) variables in the General Catalogue of Variable Stars (Samus et al. 2007-2014, GCVS). Some Ap stars also exhibit photometric variability in the period range of $\sim 5-20 \mathrm{~min}$ (high-overtone, low-degree, and non-radial pulsation modes). These stars are known as rapidly 
oscillating Ap (roAp) stars (Kurtz 1990) and are not the subject of the present paper.

Considerable effort has been devoted to the study of the photometric variability of the magnetic Ap stars by photometric investigations or by mining available sky survey data (Manfroid \& Mathys 1986; Paunzen \& Maitzen 1998; Paunzen et al. 2011; Wraight et al. 2012). The present paper investigates the photometric variability of Ap stars using the publicly available observations from the third phase of the All Sky Automated Survey (ASAS-3, Pojmański 2002) and aims at finding previously unidentified ACV variables. Observations, target selection, data analysis, and interpretation are described in Sect. 2. Results are presented and discussed in Sect. 3, and we conclude in Sect. 4.

\section{Observations and analysis}

The targets for the present investigation were primarily chosen among the Ap stars listed in the most recent version of the Catalogue of Ap, HgMn, and Am stars (Renson \& Manfroid 2009, RM09 hereafter). At the beginning of the project, a number of Am stars from the aforementioned list were inspected, too. According to our expectations, most of them did not exhibit variability in ASAS-3 data, which led us to abandon this approach and concentrate only on the Ap stars. The three Am stars that exhibit obvious light variability might actually be Ap stars which have been spectroscopically misclassified as Am stars (Sect. 3).

The RM09 catalogue was cross-matched with the Tycho-2 catalogue (Høg et al. 2000), and all objects with $V_{\mathrm{T}}<11 \mathrm{mag}$ that have a reasonable number of observations in the ASAS-3 database were investigated. These are mostly southern objects with $\delta<0^{\circ}$. Additionally, other variables of spectral type late B to early A (with or without known chemical peculiarities) that have been investigated or discovered as by-products of other projects (Otero 2007) and which exhibit photometric variability typical of ACVs were included in our investigation.

The GCVS, the AAVSO International Variable Star Index, VSX (Watson 2006), the VizieR (Ochsenbein et al. 2000), and SIMBAD (Wenger et al. 2000) databases were consulted to check for an entry in variability catalogues. Objects that have already been announced as ACV variables in the literature were dropped from our sample.

\subsection{Characteristics of the ASAS-3 data}

The All Sky Automated Survey (ASAS) is a project that aims at continuous photometric monitoring of the whole sky, with the ultimate goal of detecting and investigating any kind of photometric variability. The first two phases of the project, ASAS-1 and ASAS-2, resulted in the discovery of about 3800 variable stars (Pojmański 1998, 2000).

The third phase of the project, ASAS-3, which has produced a catalogue of about 50000 variable stars (Pojmański et al. 2005), lasted from 2000 until 2009 (Pojmański 2002) and has been monitoring the entire southern sky and part of the northern sky $\left(\delta<+28^{\circ}\right)$. The ASAS-3 system, which occupied the ten-inch astrograph dome of the Las Campanas Observatory (Chile), consisted of two wide-field telescopes equipped with f/2.8200 mm Minolta lenses and 2048×2048 AP 10 Apogee detectors, covering a field of $8.8 \times 8.8$ of sky. Data were obtained through standard Johnson $I$ and $V$ filters during the ASAS- 2 and ASAS-3 surveys, respectively. About $10^{7}$ sources brighter than about $V=14$ mag were catalogued. With a CCD resolution of about 14 .' $^{\prime}$ per pixel, the astrometric accuracy is around $3-5^{\prime \prime}$ for bright stars and up to $15^{\prime \prime}$ for fainter stars. Thus, photometry in crowded fields as in star clusters is rather uncertain.

The typical exposure time for ASAS-3 $V$-filter observations was three minutes, which resulted in reasonable photometry for stars in the magnitude range $7 \lesssim V \lesssim 14$. The all-sky character of the survey necessitated sparse sampling. In general, a field was observed each one, two, or three days (Pigulski 2014) resulting in strong daily aliases in the corresponding Fourier spectra.

The most accurate photometry was obtained for stars in the magnitude range $8 \lesssim V \lesssim 10$, exhibiting a typical scatter of about 0.01 mag (Pigulski 2014). However, because of the long time baseline of almost ten years, the detection limit of the ASAS-3 data for periodic signals is much lower than this value. David et al. (2014) have detected periodic variables with amplitudes of variability of $0.01-0.02 \mathrm{mag}$ in the magnitude range of $7 \lesssim V \lesssim 10$. Pigulski (2014) estimated that periodic signals with amplitudes as low as $4-5$ mmag can still be detected well. Thus, the ASAS-3 data are perfectly suited to an investigation of the low-amplitude photometric variability of CP stars (Manfroid \& Mathys 1986).

\subsection{Data analysis and interpretation}

The light curves of all target stars were downloaded from the ASAS-3 website ${ }^{1}$. No data from our targets exist in the ASAS-2 I-band catalogue. The light curves were inspected visually, and obvious outliers and data points with a quality flag of "D" (="worst data, probably useless") were removed. Promising candidates, i.e. stars showing a larger scatter than usually observed for apparent constant stars in the corresponding magnitude range with comparable instruments (Hartman et al. 2004), were searched for periodic signals in the frequency domain of $1<f(c / d)<30$ using Period04 (Lenz \& Breger 2005).

Objects exhibiting periodic signals well above the noise level (corresponding to a semi-amplitude of at least $\sim 0.007 \mathrm{mag}$, as determined with Period04) were investigated. The data was folded with the resulting best-fitting frequency, and the light curve was visually inspected. ASAS-3 data sometimes suffer from systematic trends. For example, strong blending effects may induce significant additional scatter due to the inclusion of part of the neighbouring star's flux, thus effectively rendering small-amplitude variations undetectable (Sitek \& Pojmański 2014). Furthermore, instrumental long-term mean brightness trends might result in the detection of spurious periods. Consequently, objects whose light curves are indicative of strong systematic trends were rejected. Stars exhibiting convincing phase plots were kept. Borderline cases - that is to say, stars exhibiting a weak signal (semi-amplitude of $\leq 0.007 \mathrm{mag}$ ) that could not be attributed to systematic trends but did not produce a convincing phase plot either - were rejected as well in order to keep the sample free of possibly spurious detections that might contaminate the sample of derived rotational periods. The object was finally classified according to spectral type, colour information, period, and shape of its light curve.

The observed variability pattern of most stars is in accordance with an ACV classification. Judging from light curve characteristics, some eclipsing or rotating ellipsoidal variables might be present, too. Because ACV variables are prone to exhibiting double-wave variations in their photometric light curves (Maitzen 1980), it is sometimes difficult to distinguish between the light curves of double-waved ACVs and the variability

http://www . astrouw.edu.pl/asas/ 
induced by orbital motion (ellipsoidal variables/eclipsing variables), especially for objects exhibiting very small amplitudes and/or significant scatter in their light curves.

Generally, there seems to be a lack of binaries among most subgroups of Ap stars (for example, the $\mathrm{Si}, \mathrm{Si}-\mathrm{Cr}$, and $\mathrm{Si}-\mathrm{Sr}$ stars, Gerbaldi et al. 1985; Leone \& Catanzaro 1999); in particular, very few double-lined spectroscopic binaries comprising an Ap star are known (Hubrig et al. 2014), and a conspicuous lack of short-period systems has been described in the literature (North \& Debernardi 2004; Hubrig et al. 2005). Furthermore, the search for magnetic Ap stars in eclipsing binary systems has mostly been to no avail. Up to 2005, no such system has ever been found (Hubrig et al. 2005). RM09 list only five bona fide candidates for eclipsing Ap stars from which one, AO Velorum, has been confirmed (González et al. 2006). In their photometric study of Ap stars with the STEREO satellites, Wraight et al. (2012) did not identify any eclipsing binaries or ellipsoidal variables among their sample of 337 stars. However, some of them show distinct double-waved light curves. Furthermore, for the spectroscopic binaries with known periods among their sample, they were not able to establish a relation between the orbital period and the period of the observed light variations.

To sum up, it seems to be well established that the incidence of ellipsoidal variables or eclipsing binaries among Ap stars is very low. Accordingly, if the observed variability pattern is in general accordance with the rotational modulation caused by spots, we are inclined to interpret double-waved light curves as due to this mechanism. However, in doubtful cases, orbital motion cannot be decisively rejected as the source of the observed variability.

In fact, we have identified some stars among our sample that we consider to be promising eclipsing binary or ellipsoidal variable candidates, which - considering the size of the sample - is expected. HD 70817 is very likely an eclipsing binary, but its status as a CP star seems to be doubtful (Skiff 2014). Multicolour photometry with higher precision and/or spectroscopic studies are needed for a final conclusive classification. This will be part of a follow-up investigation.

\section{Results}

Most of the investigated Ap stars have never been the subject of a light variability analysis before, or, as in the case of HD 263361 , they have been investigated and found constant or probably constant, and are described here as variable stars for the first time. Some of our targets have been identified as variable stars with or without a given period in the literature, but their variability types have not been determined or they have been misclassified. To the best of our knowledge, these stars are presented here as ACV variables for the first time. Interestingly, 16 of these objects already have known or suspected periods as listed in the RM09 catalogue. While this implies they are members of the class of ACV variables, these stars are not listed as known or suspected ACV variables in related papers and variability catalogues. Thus, we deemed it worthwhile to draw attention to these objects by including them in our sample.

Also included in our sample are three Am stars from the RM09 list, which exhibit light variations and periods typical of ACV variables. Two of them are marked as not likely to be CP objects in RM09. Under the assumption that these stars might possibly have been spectroscopically misclassified, we have listed them as ACV candidates (type "ACV:" in Table 2) and suggest further spectroscopic observations. The objects are flagged as Am stars in Table 4.
Table 1. Statistical information on the composition of the present sample.

\begin{tabular}{lr}
\hline \hline Type & Number of objects \\
\hline Newly discovered ACV variables & 239 \\
Variables of undetermined type $^{1}$ & 61 \\
Misclassified variables $^{1}$ & 16 \\
EB/ELL star candidates & 7 \\
Whole sample & 323 \\
\hline
\end{tabular}

Notes. ${ }^{(1)}$ Identified as ACV variables for the first time.

Some stars in our sample are listed with a twice longer or a twice shorter period in the literature. A twice longer (or shorter) rotation period cannot, in some cases, be definitely rejected for objects showing sinusoidal light variations and very small amplitudes and/or significant scatter in their light curves. However, the observed discrepancy is mostly due to classification differences. For example, some ASAS variables, which we have identified as ACV variables, have been classified as eclipsing binaries in the ASAS Catalogue of Variable Stars (ACVS) and are consequently listed there with a period that is twice as long. For very few cases, the period value listed in the literature is very different from our solution and possibly represents an alias of the real period.

We have checked the period solution of all doubtful cases (Sect. 2.2) and are confident that we have determined the period that fits ASAS-3 data best. This is also supported by the generally very good agreement of our period solutions to those from the literature. Because of the strong daily aliasing inherent to ASAS-3 data (Sect. 2.1), alias periods cannot be totally excluded.

Some stars in our sample $(N=31)$ have been spectroscopically classified as late B/early A-type stars, but have not been identified as (possible) chemically peculiar objects in the literature. Nevertheless, they have been included as ACV candidates (denoted as type "ACV:" in Table 2) in the present list of stars because of their typical photometric variability. Spectroscopic confirmation of these stars is needed to draw a final conclusion about their nature.

A part of our sample comprises Hipparcos unsolved variables (Koen \& Eyer 2002), which have been automatically classified using random forests (Dubath et al. 2011) and a multistage methodology based on Bayesian networks (Rimoldini et al. 2012, R12 hereafter). Likewise, the probabilistic classification catalogue created by Richards et al. (2012, "Machine-learned ASAS Classification Catalog (MACC)"; RS12 hereafter) lists classifications and their probabilities for the (mis- or unclassified) ASAS variables included in our sample. Since the results of the employed automatic classification routines regarding our sample of ACV variables might potentially be of interest in estimating their performance, we have included the findings of the above-mentioned investigations in the presentation of our results. For stars having an entry in R12, we list variability types predicted by both methods, following the order of the VizieR online catalogue: predicted type random forests/predicted type Bayesian networks (probability predicted by random forests/probability predicted by Bayesian networks). It is interesting to note that some of our confirmed ACV variables are listed as doubtful cases in RM09. That these objects exhibit light variations typical of ACV variables is further evidence of their peculiar nature.

Table 1 presents statistical information on the composition of the present sample, and Tables 2 to 4 list the results of the 
Table 2. Essential data for the 316 stars identified as photometrically variable chemically peculiar stars or star candidates in the present paper.

\begin{tabular}{|c|c|c|c|c|c|c|c|c|c|c|}
\hline Star & ID (RM09) & $\alpha(\mathrm{J} 2000)$ & $\delta(\mathrm{J} 2000)$ & Type & $\begin{array}{c}\text { Range }(V) \\
{[\mathrm{mag}]}\end{array}$ & $\begin{array}{l}\text { Period } \\
\text { [d] }\end{array}$ & $\begin{array}{c}\text { Epoch (HJD) } \\
{[\mathrm{d}]}\end{array}$ & & $\begin{array}{c}(B-V) \\
{[\mathrm{mag}]}\end{array}$ & $\begin{array}{c}\left(J-K_{\mathrm{s}}\right) \\
{[\mathrm{mag}]}\end{array}$ \\
\hline HD 10081 & 2510 & 013615.100 & -681505.38 & $\mathrm{ACV}$ & $9.60-9.64$ & $1.57032(3)$ & $2452190.56(3)$ & A0 Sr Eu & +0.031 & +0.041 \\
\hline HD 26726 & 6830 & 041246.635 & -244748.55 & $\mathrm{ACV}$ & $9.81-9.90$ & $5.3816(4)$ & $2451902.6(1)$ & A2 $\mathrm{Sr}$ & +0.325 & +0.006 \\
\hline HD 30898 & 7983 & 045128.382 & -003247.85 & ACV: & $7.84-7.88$ & $0.781776(8)$ & $2452185.79(2)$ & $\mathrm{A} 1-\mathrm{F} 0$ & +0.269 & +0.124 \\
\hline HD 35177 & 8980 & 052301.934 & +014148.94 & ACV & $8.12-8.15$ & $0.528194(5)$ & $2452670.60(1)$ & B9 Si & -0.068 & -0.118 \\
\hline HD 36997 & 9810 & 053513.819 & -022252.32 & ACV & $8.31-8.36$ & $6.0072(4)$ & $2453101.5(1)$ & B9 Si Sr & -0.043 & -0.060 \\
\hline HD 37189 & 9940 & 053609.774 & -134920.35 & $\mathrm{ACV}$ & $8.53-8.57$ & $2.8286(1)$ & $2452115.90(6)$ & A0 Si & -0.033 & -0.001 \\
\hline HD 37713 & 10170 & .257 & -250853.44 & $\mathrm{ACV}$ & $8.11-8.14$ & $1.50125(3)$ & $2451914.64(3)$ & B9 Si & -0.054 & -0.243 \\
\hline HD 3 & 10320 & 682 & +091900.77 & ACV & 8.94 & $0.625264(5)$ & $2454143.68(1)$ & B9 Si & +0.009 & +0.051 \\
\hline HD 3 & 10400 & 86 & -142 & ACV & $9.09-9.12$ & $3.1643(2)$ & $90.64(6)$ & A0 Si & -0.003 & +0.011 \\
\hline HD & & 32 & -10 & ACV: & 8.7 & (2) & $51(8)$ & $\mathrm{A} 0(\mathrm{~V})$ & 978 & +0.382 \\
\hline $\mathrm{HD}$ & 11300 & 061 & +032 & $\mathrm{ACV}$ & 9.1 & $5.9277(7)$ & $9(2)$ & B9 Cr Eu Si & 56 & 019 \\
\hline $\mathrm{HD}$ & 11420 & 061 & -22 & $\mathrm{ACV}$ & 8.1 & $1.06877(2)$ & 245514 & B9 Si & 35 & -0.015 \\
\hline HD 44038 & 11668 & 061910.142 & -092206.21 & $\mathrm{ACV}$ & $9.73-9.77$ & $0.689929(6)$ & $2453029.75(1)$ & $\mathrm{A} 0 \mathrm{Eu} \mathrm{Cr} \mathrm{Sr}$ & +0.033 & +0.014 \\
\hline HD 44290 & 11750 & 062 & -141148.34 & $\mathrm{ACV}$ & $8.52-8.55$ & $1.71523(4)$ & $2452032.48(3)$ & B9 Cr Eu & +0.026 & -0.031 \\
\hline HD 44456 & 11800 & 062155.420 & 15.18 & $\mathrm{ACV}$ & $8.50-8.54$ & $3.8934(2)$ & $2452243.73(8)$ & A0 Si Sr & +0.000 & -0.016 \\
\hline HD 2 & 12200 & 062914.344 & +004257.01 & ACV & $9.75-9.78$ & $2.7305(2)$ & $2453457.57(8)$ & B9 Si & -0.005 & +0.067 \\
\hline HD 258583 & 12260 & 063022.290 & +083936.98 & ACV & $8.76-8.83$ & $10.312(1)$ & $2452671.6(2)$ & A0 Si & -0.012 & -0.048 \\
\hline HD 45931 & 12280 & 063027.489 & -002221.41 & ACV & $8.95-9.00$ & $1.92699(5)$ & $2452199.82(4)$ & A0 Si & +0.058 & -0.017 \\
\hline HD 46234 & 12370 & 063032.021 & -384510.22 & ACV & $9.28-9.31$ & $4.6936(4)$ & $2451924.6(1)$ & A0 Si & -0.105 & -0.052 \\
\hline HD 47026 & 12590 & 063358.822 & -480902.09 & $\mathrm{ACV}$ & $9.51-9.56$ & $1.28037(2)$ & $2452143.88(2)$ & B9 $\mathrm{Sr} \mathrm{Cr} \mathrm{Eu}$ & +0.014 & -0.006 \\
\hline
\end{tabular}

Notes. Only part of the table is printed here for guidance regarding its form and content. The complete table is given in the Appendix.

Table 3. Essential data for the 7 stars identified as promising eclipsing binary or ellipsoidal variable star candidates in the present paper.

\begin{tabular}{|c|c|c|c|c|c|c|c|c|c|c|}
\hline Star & ID (RM09) & $\alpha(\mathrm{J} 2000)$ & $\delta(\mathrm{J} 2000)$ & Type & $\begin{array}{c}\text { Range }(V) \\
{[\mathrm{mag}]}\end{array}$ & $\begin{array}{l}\text { Period } \\
\text { [d] }\end{array}$ & $\begin{array}{c}\text { Epoch (HJD) } \\
{[\mathrm{d}]}\end{array}$ & & $\begin{array}{l}(B- \\
{[\mathrm{ma}}\end{array}$ & $\begin{array}{c}\left(J-K_{\mathrm{s}}\right) \\
{[\mathrm{mag}]}\end{array}$ \\
\hline HD 57526 & 15710 & 072052.724 & -213430.25 & $\overline{\mathrm{ACV} / \mathrm{EB}}$ & $8.33-8.37$ & $3.3446(2)$ & $2452702.65(7), \min$ & B9 Si & -0.040 & -0.035 \\
\hline HD 64881 & 17800 & 075359.051 & -453835.78 & $\mathrm{ACV} / \mathrm{ELL}$ & $8.79-8.83$ & $1.1039(2)$ & $2453057.62(2), \max$ & $\mathrm{A} 0 \mathrm{Si}$ & -0.033 & -0.024 \\
\hline HD 70817 & 19540 & 082233.328 & -392823.44 & EB & $9.30-9.45$ & $3.50859(1)$ & 2454 181.730(4), min & B9 $\mathrm{Si}$ & +0.201 & +0.194 \\
\hline HD 97986 & 28260 & 111449.418 & -702137.66 & $\mathrm{ACV} / \mathrm{ELL}$ & $7.84-7.90$ & $4.3538(3)$ & $2451878.79(8), \max$ & B8 Si & +0.046 & -0.011 \\
\hline HD 133246 & 37830 & 150530.511 & -533153.40 & ACV/ELL & $9.05-9.10$ & $1.79858(4)$ & $2451953.79(4), \max$ & B9 Si & +0.041 & -0.024 \\
\hline HD 161724 & 45640 & 175029.078 & -563429.24 & $\mathrm{ACV} / \mathrm{EB}$ & $9.60-9.67$ & $5.6882(4)$ & $2452067.6(1), \min$ & B9 $\mathrm{Si}$ & -0.039 & -0.028 \\
\hline HD 174595 & 48860 & 185204.499 & -203617.10 & $\mathrm{ACV} / \mathrm{EB}$ & $9.08-9.17$ & $7.1142(7)$ & $2452464.6(1), \min$ & A0 Si & +0.095 & -0.031 \\
\hline
\end{tabular}

Table 4. Available information on single objects from the literature and miscellaneous remarks.

\begin{tabular}{|c|c|c|c|c|c|c|}
\hline Star & $\begin{array}{l}\text { Var. desig. } \\
\text { literature }\end{array}$ & $\begin{array}{l}\text { Var. type } \\
\text { literature }\end{array}$ & $\begin{array}{l}\text { Period }(\mathrm{d}) \\
\text { literature }\end{array}$ & $\begin{array}{l}\text { Period }(\mathrm{d}) \\
\text { this work }\end{array}$ & Reference & $\begin{array}{l}\text { Remarks/comments } \\
\text { literature }\end{array}$ \\
\hline HD 30898 & NSV 16178 & VAR & 3.61890 (VSX), 0.782 (RM09) & $0.781776(8)$ & van Leeuwen et al. (1997) & RM09: Am star \\
\hline HD 35177 & HIP 25163 & VAR & 0.52820 (VSX) & $0.528194(5)$ & Koen \& Eyer (2002) & \\
\hline HD 36997 & NSV 16417 & VAR: & $\mathrm{n} / \mathrm{a}$ & $6.0072(4)$ & Olsen (1983) & \\
\hline HD 38366 & ASAS J054533+0919.0 & RRAB & 0.62528 (VSX) & $0.625264(5)$ & Pojmański (2002) & RS12: ACV (prob: 0.7498 ) \\
\hline HD 39635 & NSV 16723 & VAR & 3.96574 (VSX) & $3.9660(2)$ & van Leeuwen et al. (1997) & R12: BE+GCAS/BE+GCAS (prob: 0.27/0.60) \\
\hline HD 44456 & ASAS J062155+0018.3 & $\mathrm{ED}, \mathrm{ESD}$ & 7.78607 (VSX) & $3.8934(2)$ & Pojmański (2002) & RS12: ACV (prob 0.5627) \\
\hline HD 47714 & HIP 31851 & $\mathrm{n} / \mathrm{a}$ & $4.6946(\mathrm{R} 12)$ & $4.6953(4)$ & $\mathrm{R} 12$ & R12: ACV/ACV (prob: 0.26/0.79) \\
\hline HD 263361 & & & & $88.9(1)$ & & $\begin{array}{l}\text { Constant or probably constant according } \\
\text { to Wraight et al. (2012); period is outside their } \\
\text { considered frequency domain }\end{array}$ \\
\hline HD 50391 & & & & $1.18285(3)$ & & $*$ \\
\hline HD 50461 & NSV 17218 & VAR & 0.89410 (VSX) & $0.89403(2)$ & van Leeuwen et al. (1997) & R12: SPB/SPB (prob: 0.63/0.62) \\
\hline HD 50855 & HIP 33125 & $\mathrm{n} / \mathrm{a}$ & 2.24027 (R12) & $2.23913(6)$ & & R12: BE+GCAS/BE+GCAS (prob: 0.56/0.56) \\
\hline HD 50895 & HIP 33164 & VAR & 3.58989 (VSX) & $3.5902(2)$ & Koen \& Eyer (2002) & R12: BE+GCAS/ACV (prob: 0.44/0.56) \\
\hline HD 51031 & ASAS J065504-1629.7 & DCEP-FO & $2.364(\mathrm{VSX})$ & $2.36431(9)$ & Pojmański (2002) & RS12: ACV (prob: 0.8802) \\
\hline HD 51303 & ASAS J065645-0055.0 & VAR & 4.508258 (VSX) & $4.5076(3)$ & Pojmański (2000) & \\
\hline HD 52567 & LR CMa & ACYG: & $11.942(\mathrm{VSX})$ & $11.9467(9)$ & van Leeuwen et al. (1997) & $\begin{array}{l}\text { Dubath et al. (2011): likely ACV; } \\
\text { RS12: ACV (prob: } 0.9641 \text { ) }\end{array}$ \\
\hline HD 53204 & NSV 17317 & $\mathrm{n} / \mathrm{a}$ & $4.2462(\mathrm{R} 12)$ & $2.28534(7)$ & van Leeuwen et al. (1997) & R12: BE+GCAS/ACV (prob: 0.42/0.62) \\
\hline HD 53695 & HIP 34175 & VAR & 0.09964 (VSX) & $0.83891(2)$ & Koen \& Eyer (2002) & $*$ \\
\hline HD 53851 & HIP 34283 & VAR & 2.02446 (VSX), 4.049? (RM09) & $2.02464(5)$ & Koen \& Eyer (2002) & R12: SPB/SPB (prob: $0.50 / 0.80$ ) \\
\hline
\end{tabular}

Notes. An asterisk in Col. 7 denotes stars whose status as chemically peculiar objects is doubtful according to RM09. Only part of the table is printed here for guidance regarding its form and content. The complete table is given in the Appendix. 
present investigation and are presented in their entirety in the Appendix. Tables 2 and 3 present essential data for the 323 stars we have identified as photometrically variable magnetic Ap stars or star candidates. The tables are organized as follows:

- Column 1: star name, HD number, or other conventional identification.

- Column 2: identification number from RM09.

- Column 3: right ascension (Tycho-2).

- Column 4: declination (Tycho-2).

- Column 5: variability type, $\alpha^{2}$ Canum Venaticorum (ACV), eclipsing binary (EB), and ellipsoidal (ELL).

- Column 6: $V$ magnitude range.

- Column 7: period (d).

- Column 8: epoch (HJD). In Table 3, this column also specifies the type of epoch. (Time of minimum is given for likely eclipsing binary or ellipsoidal variable star candidates, time of maximum for likely ACV variables.)

- Column 9: spectral classification, as listed in RM09 and - for the objects not contained in this list - Buscombe (1998, HD 39635), Cannon \& Pickering (1993, HD 52567, HD 88488, HD 89726, HD 166417, and HD 177548), Ochsenbein (1980, HD 61134, HD 77013, HD 82691, HD 169005, and HD 299070), Skiff (2014), and Sundman et al. (1974, TYC $8690-1870-1)$. It is noteworthy that, as in the original paper, the "p" denoting peculiarity has been omitted from the spectral classifications taken from RM09.

- Column 10: $(B-V)$ index, taken from Kharchenko (2001).

- Column 11: $\left(J-K_{\mathrm{s}}\right)$ index, as derived from the 2MASS catalogue (Skrutskie et al. 2006).

Table 4 lists available information from the literature and miscellaneous remarks on individual objects. It is organized as follows:

- Column 1: star name, HD number or other conventional identification.

- Column 2: variable star designation from the literature.

- Column 3: variable star type from the literature.

- Column 4: period (d) from the literature.

- Column 5: period (d) from this paper.

- Column 6: reference in which - to the best of our knowledge - the object has been announced as a variable star for the first time.

- Column 7: remarks of a miscellaneous nature: an asterisk denotes stars, whose status as chemically peculiar objects is doubtful according to RM09.

The light curves of all objects, folded with the period listed in Tables 2 and 3, are presented in the Appendix.

\subsection{Statistical analyses}

Because the source of our investigation, the RM09 catalogue, is rather inhomogeneous, the present sample is not very suitable for a statistical analysis. However, to compare our results with those of other, similar investigations, we have included some informative plots. In the following, we do not include objects whose status as ACV variables remains doubtful (Table 3).

Figure 1 investigates the distribution of the logarithmic rotational periods (upper panel) and the $V$ magnitude ranges (lower panel) of the photometrically variable Ap stars and Ap star candidates of our sample. Our results are in excellent agreement with the literature, illustrating the well-known peak around $\log P=0.4$ days (compare, for example, Fig. 7 of RM09) and the magnitude range of the variations (Mathys \& Manfroid 1985).
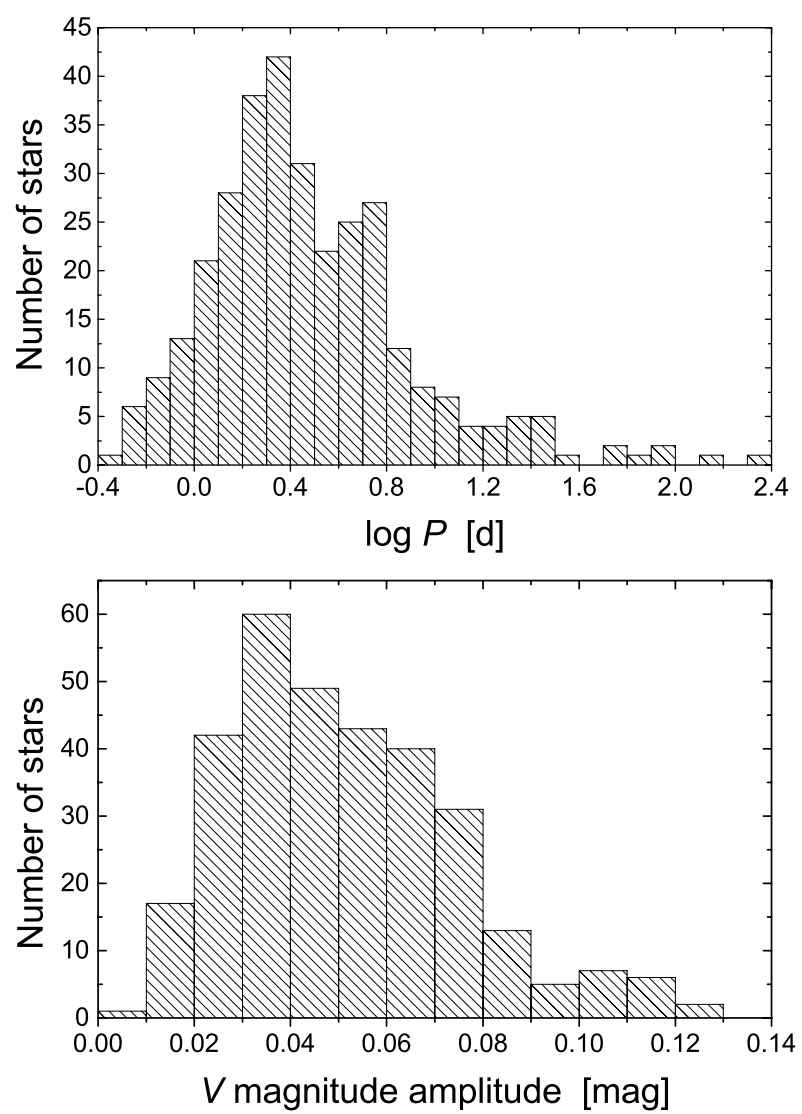

Fig. 1. Distribution of the logarithmic rotational periods (upper panel) and $V$ magnitude amplitudes (lower panel) among the photometrically variable Ap stars and Ap star candidates of the present sample (Table 2).

It is worthwhile pointing out, though, that the observed sharp decrease in numbers below a $V$ magnitude range $<0.03$ mag is at least partially due to observational bias, since the ASAS-3 measurement uncertainties approach this value for the fainter objects, thus preventing the detection of very low-amplitude variables among the fainter stars. We want to stress that we might have missed some very low amplitude variations due to the selection and analysis process (Sect. 2.2). The rotational periods of Ap stars are more or less restricted to a rather narrow range. In light of the oblique rotator model, this means that a stable magnetic field configuration, which is needed to generate surface spots, can only survive for a distinct range of equatorial rotational velocities. For a detailed analysis of this important topic, one needs masses, luminosities, ages, and the inclination angles of rotating stars. This information cannot be straightforwardly determined from photometric data alone.

Figure 2 (upper panels) shows the colour indices $\left(J-K_{\mathrm{s}}\right)$ and $(B-V)$ versus the logarithmic rotational periods. It is a matter of debate and even some controversy in the literature whether there should be a correlation or not. While RM09 found no correlation between the periods and the $(B-V)$ colours for their extended sample (see their Fig. 8), Mikulášek et al. (2009) reached the conclusion that cooler magnetic CP stars (such as $\mathrm{SrCrEu}$ stars) rotate more slowly (see their Fig. 2). Of course, relying solely on colour information simplifies the problem dramatically. This approach does not take the luminosity into account, as well as the mass and thus evolutionary effects. We investigated such a possible simple colour correlation by employing a linear regression. We chose to restrict the colour index range to the most densely populated region of the diagram, which corresponds to 

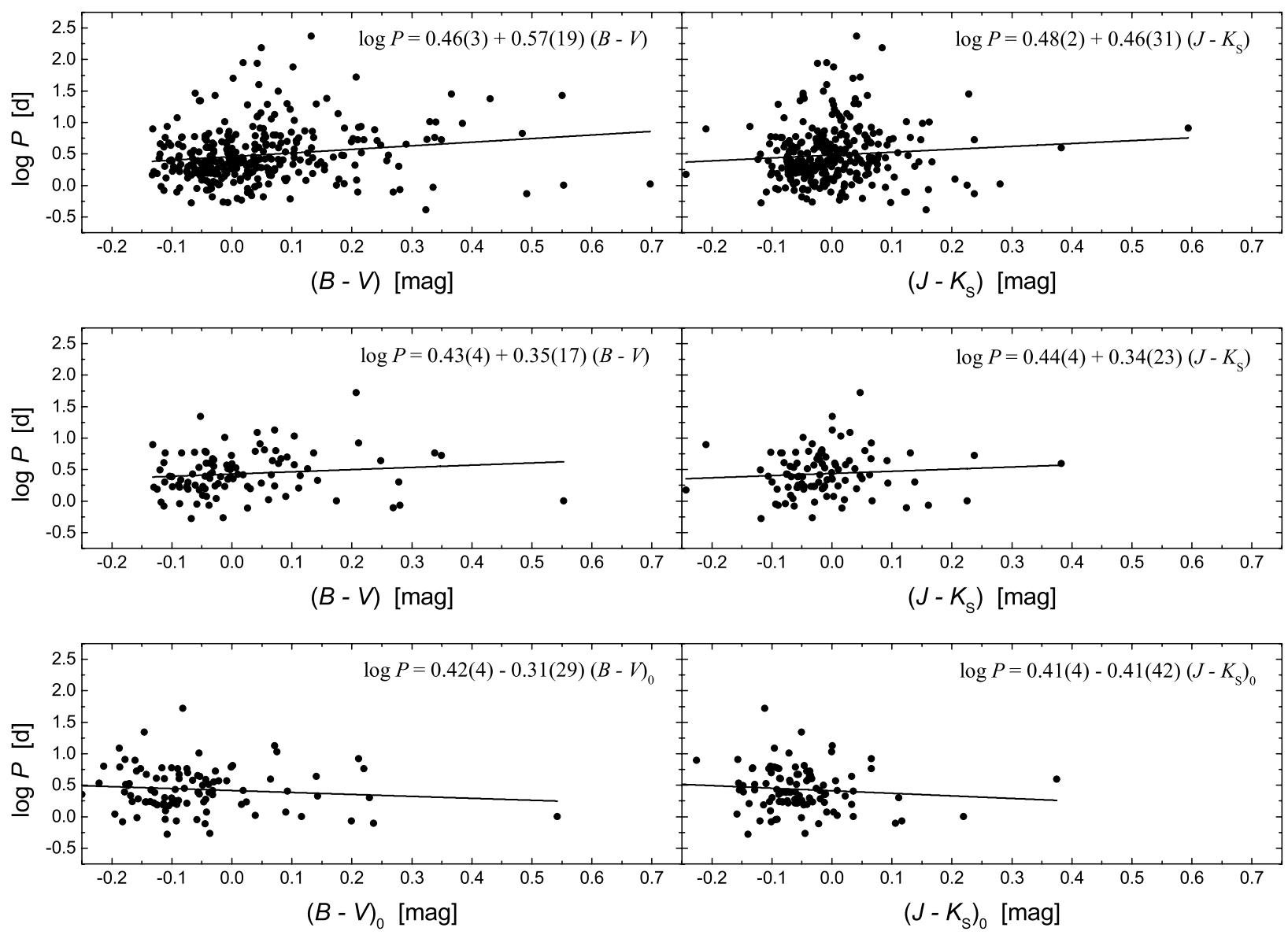

Fig. 2. Rotational periods as a function of $(B-V)$ and $\left(J-K_{\mathrm{s}}\right)$ of the photometrically variable Ap stars and Ap star candidates of the complete sample (upper panels) and the 99 stars of our sample for which we were able to determine the reddening (middle and lower panels; Table 5).

$(B-V) \leq 0.25 \mathrm{mag}$. This also allowed us a direct comparison with Fig. 2 of Mikulášek et al. (2009). In agreement with the findings of these investigators, we found a possible weak correlation between the rotational period and $(B-V)$ index ( $t$ parameter of 3.87), in the sense that cooler magnetic $\mathrm{CP}$ stars rotate more slowly. The slope was estimated as 0.57(19).

However, the reddening for our sample cannot be neglected. Most of our stars are located in the Galactic disk with a Galactic latitude $|b|<10^{\circ}$ and $7 \lesssim V \lesssim 10 \mathrm{mag}$. For an A0 star with $M_{V} \sim 0$ mag, this corresponds to distances between 250 and $1000 \mathrm{pc}$. In the Galactic disk, an absorption of $A_{V}(=3.1 E(B-$ $V)=5.636 E\left(J-K_{\mathrm{s}}\right)$ ) of about $2 \mathrm{mag} \mathrm{kpc}^{-1}$ was observed for some regions (Chen et al. 1998; Dutra et al. 2002).

The reddening for the targets was estimated using photometric calibrations in the Strömgren $u v b y \beta$ (Crawford 1978, 1979 ) and the $Q$-parameter within the Johnson $U B V$ system (Johnson 1958). These methods are only based on photometric indices and do not take any distance estimates via parallax measurements into account. Photometric data were taken from the General Catalogue of Photometric Data $\left(\mathrm{GCPD}^{2}\right)$. Where possible, averaged and weighted mean values were used throughout. For stars with Hipparcos parallax measurements (van Leeuwen 2007) with a precision better than $30 \%$, the distance and Galactic coordinates were used to determine the reddening from the extinction model by Amorres \& Lépine (2005). If several estimates were available, they were compared and yielded excellent agreement. Table 5 lists the reddening values of the 99 stars for which

\footnotetext{
2 http://obswww. unige.ch/gcpd/
}

we are able to determine the reddening. For the remaining stars neither photometry nor accurate parallaxes are available. The values for $A_{V}$ reach up to $1.5 \mathrm{mag}$.

As described above, we then employed a linear regression to the dereddened sample (Fig. 2, lower panels). No significant slope was found for this data sample. This could be interpreted as introducing a severe bias in the correlation when neglecting the reddening. To exclude the possibility of a selection effect, we also investigated the reddened colours of the sample from Table 5.

Although the slopes are slightly shallower, they are still significant (Fig. 2, middle panels). To verify our results, we investigated the behaviour of the correlation using Tycho-2 data instead of Kharchenko (2001) data, which led to the same conclusions. Furthermore, we employed the Spearman rank-order correlation coefficient (Spearman 1904), a non-parametric measure of correlation, to investigate our results. For this, we divided our sample (Table 2) into four groups using $\log P$ and $(B-V)$ :

- All stars, reddened: $\rho=+0.20, p=0.0004, N=316$,

- All stars with $(B-V) \leq 0.25$ mag, reddened: $\rho=+0.21$, $p=0.0002, N=295$,

- All stars, unreddened: $\rho=-0.05, p=0.59, N=99$,

- All stars, with $(B-V)_{0} \leq 0.25$ mag, unreddened: $\rho=-0.03$, $p=0.76, N=98$.

The two reddened samples show, with almost $100 \%$ probability, that there is a weak correlation that is not due to random sampling. In contrast, the other two samples are, with high probability, uncorrelated. Therefore, from a statistical point of view, the 
Table 5. Reddening values derived for 99 stars of our sample from $U B V$ and $u v b y \beta$ photometry as well as the extinction model by Amores \& Lépine (2005); $A_{V}\left(=3.1 E(B-V)=5.636 E\left(J-K_{\mathrm{S}}\right)\right)$.

\begin{tabular}{|c|c|c|c|c|c|c|c|}
\hline Star & $\begin{array}{c}E(B-V) \\
{[\mathrm{mag}]}\end{array}$ & Star & $\begin{array}{c}E(B-V) \\
{[\mathrm{mag}]}\end{array}$ & Star & $\begin{array}{c}E(B-V) \\
{[\mathrm{mag}]}\end{array}$ & Star & $\begin{array}{c}E(B-V) \\
{[\mathrm{mag}]}\end{array}$ \\
\hline CD-44 3656 & 0.022 & HD 53021 & 0.022 & HD 88488 & 0.081 & HD 138773 & 0.170 \\
\hline CPD-60 944A & 0.000 & HD 53204 & 0.017 & HD 88757 & 0.142 & HD 144815 & 0.166 \\
\hline HD 10081 & 0.015 & HD 53695 & 0.069 & HD 89519 & 0.000 & HD 146555 & 0.138 \\
\hline HD 30898 & 0.033 & HD 53851 & 0.000 & HD 92190 & 0.062 & HD 148848 & 0.000 \\
\hline HD 35177 & 0.040 & HD 54544 & 0.025 & HD 92379 & 0.000 & HD 149831 & 0.178 \\
\hline HD 36997 & 0.057 & HD 56273 & 0.034 & HD 92849 & 0.029 & HD 154645 & 0.098 \\
\hline HD 37189 & 0.046 & HD 56748 & 0.055 & HD 93821 & 0.007 & HD 155313 & 0.252 \\
\hline HD 37713 & 0.051 & HD 56773 & 0.071 & HD 94873 & 0.000 & HD 157063 & 0.225 \\
\hline HD 38698 & 0.046 & HD 57372 & 0.029 & HD 96910 & 0.000 & HD 157644 & 0.121 \\
\hline HD 39635 & 0.014 & HD 57946 & 0.084 & HD 98486 & 0.225 & HD 157678 & 0.024 \\
\hline HD 44290 & 0.002 & HD 59437 & 0.029 & HD 99204 & 0.096 & HD 158596 & 0.049 \\
\hline HD 44456 & 0.043 & HD 59752 & 0.099 & HD 103844 & 0.289 & HD 161349 & 0.070 \\
\hline HD 47714 & 0.056 & HD 61622 & 0.054 & HD 105457 & 0.207 & HD 166198 & 0.041 \\
\hline HD 48729 & 0.021 & HD 62535 & 0.035 & HD 106688 & 0.144 & HD 169005 & 0.169 \\
\hline HD 50221 & 0.028 & HD 62632 & 0.032 & HD 111055 & 0.011 & HD 174646 & 0.000 \\
\hline HD 50391 & 0.000 & HD 64901 & 0.013 & HD 112528 & 0.118 & HD 180029 & 0.303 \\
\hline HD 50461 & 0.000 & HD 83002 & 0.041 & HD 115789 & 0.000 & HD 181550 & 0.038 \\
\hline HD 50540 & 0.000 & HD 84001 & 0.022 & HD 119716 & 0.027 & HD 187128 & 0.040 \\
\hline HD 50895 & 0.000 & HD 84448 & 0.058 & HD 123627 & 0.107 & HD 258583 & 0.043 \\
\hline HD 51088 & 0.000 & HD 84656 & 0.075 & HD 123927 & 0.211 & HD 289186 & 0.010 \\
\hline HD 51172 & 0.011 & HD 85453 & 0.068 & HD 125903 & 0.047 & HD 299070 & 0.287 \\
\hline HD 51307 & 0.051 & HD 85469 & 0.029 & HD 128840 & 0.205 & HD 305451 & 0.225 \\
\hline HD 51426 & 0.053 & HD 85629 & 0.035 & HD 132988 & 0.021 & HD 315873 & 0.508 \\
\hline HD 51790 & 0.040 & HD 88343 & 0.094 & HD 138151 & 0.166 & HD 342867 & 0.027 \\
\hline HD 52589 & 0.000 & HD 88385 & 0.053 & HD 138519 & 0.229 & & \\
\hline
\end{tabular}

derived coefficients substantiate our prior conclusions. Clearly, a larger sample of CP stars with available rotational periods, along with precise stellar astrophysical parameters, is needed to investigate this topic further.

\section{Conclusions}

We have searched for photometric variability in confirmed or suspected Ap stars from the most recent version of the Catalogue of Ap, HgMn, and Am stars (RM09) using publicly available observations from the ASAS-3 database. We presented a sample of 323 photometrically variable magnetic Ap stars or star candidates, 246 of which are - to the best of our knowledge described here as variable stars for the first time. A part of our sample (31 stars) is made up of late B to early A-type variables that are not included in the RM09 catalogue and that lack confirmation of their chemical peculiarity. They were included as ACV candidates because of their typical photometric variability but need spectroscopic confirmation.

We have compared our sample with the findings of similar investigations and find very good agreement. The well-known peak around $P=2$ days in the distribution of rotational periods was confirmed. We found a possible weak correlation between rotational period and $(B-V)$ index, in that cooler magnetic $\mathrm{CP}$ stars rotate more slowly. However, this correlation seems to disappear when correcting for the interstellar reddening.

In agreement with the findings of David et al. (2014) and Pigulski (2014), we conclude that ASAS-3 data are well suited to investigating variable stars with rather low photometric amplitudes.

Acknowledgements. This project is financed by the SoMoPro II programme (3SGA5916). The research leading to these results received a financial grant from the People Programme (Marie Curie action) of the Seventh Framework Programme of the EU according to REA Grant Agreement No. 291782. The research is further co-financed by the South-Moravian Region. It was also supported by grant 7AMB14AT015 and the financial contributions of the Austrian Agency for International Cooperation in Education and Research (BG-03/2013 and CZ-09/2014). We thank the referee, Luca Fossati, for helpful comments and suggestions that helped to improve the paper. This work reflects only the author's views so the European Union is not liable for any use that may be made of the information contained therein.

\section{References}

Amorres, E. B., \& Lépine, J. R. D. 2005, AJ, 130, 659

Balona, L. A., Catanzaro, G., \& Abedigamba, O. P. 2015, MNRAS, 448, 1378 Buscombe, W. 1998, VizieR Online Data Catalog: 13th General Catalogue of MK Spectral Classification

Cannon, A. J., \& Pickering, E. C. 1993, VizieR Online Data Catalog: Henry Draper Catalogue and Extension

Chen, B., Vergely, J. L., Valette, B., \& Carraro, G. 1998, A\&A, 336, 137 Christiansen, J. L., Derekas, A., Kiss, L. L., et al. 2008, MNRAS, 385, 1749

Cousins, A. W. J., \& Stoy, R. H. 1962, Royal Observ. Bull., 49, 3

Crawford, D. L. 1978, AJ, 83, 48

Crawford, D. L. 1979, AJ, 84, 1858

David, M., Hensberge, H., \& Nitschelm, C. 2014, J. Astronomical Data, 20, 5

Dutra, C. M., Santiago, B. X., \& Bica, E. 2002, A\&A, 381, 219

Dubath, P., Rimoldini, L., \& Süveges, M. 2011, MNRAS, 414, 2602

Elkin, V. G., Kurtz, D. W., \& Nitschelm, C. 2012, MNRAS, 420, 2727

Eggen, O. J. 1983, MNRAS, 204, 377

Gerbaldi, M., Floquet, M., \& Hauck, B. 1985, A\&A, 146, 341

González, J. F., Hubrig, S., Nesvacil, N., et al. 2006, A\&A, 449, 327

Hartman, J. D., Bakos, G., Stanek, K. Z., \& Noyes, R. W. 2004, AJ, 128, 1761

Høg, E., Fabricius, C., Makarov, V. V., et al. 2000, A\&A, 355, 27

Hubrig, S., Ageorges, N., \& Schoeller, M. 2005, in Proc. of Multiple Stars across the H-R Diagram, ESO Astrophysics Symposia, ArXiv e-prints [arXiv: astro-ph/0510302]

Hubrig, S., Carroll, T. A., \& González, J. F. 2014, MNRAS, 440, 6

Johnson, H. L. 1958, Lowell Obs. Bull., 4, 37

Kharchenko, N. V. 2001, Kinematika i Fizika Nebesnykh Tel, 17, 409

Kochukhov, O. 2011, in IAU Symp. 273, eds. D. Prasad Choudhary, \& K. G. Strassmeier, 249

Kochukhov, O., \& Wade, G. A. 2010, A\&A, 513, A13

Koen, C., \& Eyer, L. 2002, MNRAS, 331, 45

Krtička, J., Janík, J., Marková, H., et al. 2013, A\&A, 556, A18

Kurtz, D. W. 1990, ARA\&A, 28, 607 
A\&A 581, A138 (2015)

Lenz, P., \& Breger, M. 2005, Commun. Asteroseismol., 146, 53

Leone, F., \& Catanzaro, G. 1999, A\&A, 343, 273

Lloyd Evans, T., Koen, M. C. J., \& Hultzer, A. A. 1983, South Africa Astron.

Obs. Circ., 7, 82

Loden, L. O., \& Sundman, A. 1989, JA\&A, 10, 183

MacConnell, D. J. 1981, A\&AS, 44, 387

Maitzen, H. M. 1980, A\&A, 89, 230

Maitzen, H. M., \& Hensberge, H. 1981, A\&A, 96, 151

Mathys, G., \& Manfroid, J. 1985, A\&AS, 60, 17

Menzies, J. W., Marang, F., \& Westerhuys, J. E. 1990, South Africa Astron. Obs. Circ., 14, 33

Michaud, G., Charland, Y., \& Megessier, C. 1981, A\&A, 103, 244

Mikulášek, Z., Szász, G., Krtička, J., et al. 2009, ArXiv e-prints [arXiv: 0905.2565]

Manfroid, J., \& Mathys, G. 1986, A\&AS, 64, 9

Morel, T., Briquet, M., Auvergne, M. et al. 2014, A\&A, 561, A35

Nichols, J. S., Henden, A. A., Huenemoerder, D. P., et al. 2010, ApJS, 188, 473

North, P., \& Debernardi, Y. 2004, in Spectroscopically and Spatially Resolving the Components of the Close Binary Stars, eds. R.W. Hilditch, H. Hensberge, \& K. Pavlovski, ASP Conf. Ser., 318, 297

Ochsenbein, F. 1980, Bulletin d'Information du Centre de Donnees Stellaires, 19,74

Ochsenbein, F., Bauer, P., \& Marcout, J. 2000, A\&AS, 143, 23 (VizieR)

Olsen, E. H. 1983, A\&AS, 54, 55

Otero, S. A. 2007, Open European Journal on Variable Stars, 72, 1

Paunzen, E., \& Maitzen, H. M. 1998, A\&AS, 133, 1

Paunzen, E., Hensberge, H., Maitzen, H. M., et al. 2011, A\&A, 525, A16

Paunzen, E., Wraight, K. T., Fossati, L., et al. 2013, MNRAS, 429, 119

Pigulski, A. 2014, in IAU Symp. 301, eds. J. A. Guzik, W. J. Chaplin, G. Handler, \& A. Pigulski, 31
Pojmański, G. 1998, Acta Astron., 48, 35 Pojmański, G. 2000, Acta Astron., 50, 177

Pojmański, G. 2002, Acta Astron., 52, 397

Pojmański, G., Pilecki, B., \& Szczygiel, D. 2005, Acta Astron., 55, 275

Preston, G. W. 1974, ARA\&A, 12, 257

Renson, P., \& Manfroid, J. 2009, A\&A, 498, 961

Richards, J. W., Starr, D. L., Miller, A. A., et al. 2012, ApJS, 203, 32

Richer, J., Michaud, G., \& Turcotte, S. 2000, ApJ, 529, 338

Rimoldini, L., Dubath, P., Süveges, M., et al. 2012, MNRAS, 427, 2917

Samus, N. N., Durlevich, O. V., Kazarovets, E. V., et al. 2007-2014, General Catalogue of Variable Stars, VizieR On-line Catalog, http://cdsarc. u-strasbg.fr/viz-bin/Cat?B/gcvs

Sitek, M., \& Pojmański, G. 2014, Acta Astron., 64, 115

Skiff, B. A. 2014, Catalogue of Stellar Spectral Classifications, VizieR Online Data Catalog, http: //cdsarc.u-strasbg.fr/viz-bin/VizieR? - source=B/mk

Skrutskie, M. F., Cutri, R. M., Stiening, R., et al. 2006, AJ, 131, 1163

Spearman, C. 1904, Am. J. Psychol., 15, 201

Stibbs, D. W. N. 1950, MNRAS, 110, 395

Sundman, A., Loden, L. O., \& Nordström, B. 1974, A\&AS, 16, 445

Turcotte, S. 2003, in Magnetic Fields in O, B and A Stars: Origin and Connection to Pulsation, Rotation and Mass Loss, eds. L. A. Balona, H. F. Henrichs, \& R. Medupe, ASP Conf. Ser., 305, 199

van Leeuwen, F. 2007, A\&A, 474, 653

van Leeuwen, F., Evans, D. W., Grenon, M., et al. 1997, A\&A, 323, L61

Vogt, N., \& Faundez, A. M. 1979, A\&AS, 36, 477

Wenger, M., Ochsenbein, F., Egret, D., et al. 2000, A\&AS, 143, 9 (SIMBAD)

Watson, C. L. 2006, Society for Astronomical Sciences Annual Symposium, 25 47 ("AAVSO International Variable Star Index"; VSX)

Wraight, K. T., Fossati, L., Netopil, M., et al. 2012, MNRAS, 420, 757 
K. Bernhard et al.: A search for photometric variability in mCP stars using ASAS-3 data

Appendix A: Complete Table 2

Table A.1. Essential data for the 316 stars identified as photometrically variable chemically peculiar stars or star candidates in the present paper.

\begin{tabular}{|c|c|c|c|c|c|c|c|c|c|c|}
\hline Star & ID (RM09) & $\alpha(\mathrm{J} 2000)$ & $\delta(\mathrm{J} 2000)$ & Type & $\begin{array}{c}\text { Range }(V) \\
{[\mathrm{mag}]}\end{array}$ & $\begin{array}{l}\text { Period } \\
\text { [d] }\end{array}$ & $\begin{array}{c}\text { Epoch (HJD) } \\
{[\mathrm{d}]}\end{array}$ & Spectral type & $\begin{array}{c}(B-V) \\
{[\mathrm{mag}]}\end{array}$ & $\begin{array}{c}\left(J-K_{\mathrm{s}}\right) \\
{[\mathrm{mag}]}\end{array}$ \\
\hline HD 10081 & 2510 & 013615.100 & -681505.38 & $\mathrm{ACV}$ & $9.60-9.64$ & $1.57032(3)$ & $2452190.56(3)$ & $\mathrm{A} 0 \mathrm{Sr} \mathrm{Eu}$ & +0.031 & +0.041 \\
\hline HD 26726 & 6830 & 041246.635 & -244748.55 & $\mathrm{ACV}$ & $9.81-9.90$ & $5.3816(4)$ & $2451902.6(1)$ & $\mathrm{A} 2 \mathrm{Sr}$ & +0.325 & +0.006 \\
\hline HD 30898 & 7983 & 045128.382 & -003247.85 & ACV: & $7.84-7.88$ & $0.781776(8)$ & $2452185.79(2)$ & $\mathrm{A} 1-\mathrm{F} 0$ & +0.269 & +0.124 \\
\hline HD 35177 & 8980 & 052301.934 & +014148.94 & $\mathrm{ACV}$ & $8.12-8.15$ & $0.528194(5)$ & $2452670.60(1)$ & B9 $\mathrm{Si}$ & -0.068 & -0.118 \\
\hline HD 36997 & 9810 & 053513.819 & -022252.32 & $\mathrm{ACV}$ & $8.31-8.36$ & $6.0072(4)$ & $2453101.5(1)$ & B9 $\mathrm{Si} \mathrm{Sr}$ & -0.043 & -0.060 \\
\hline HD 37189 & 9940 & 053609.774 & -134920.35 & $\mathrm{ACV}$ & $8.53-8.57$ & $2.8286(1)$ & $2452115.90(6)$ & $\mathrm{A} 0 \mathrm{Si}$ & -0.033 & -0.001 \\
\hline HD 37713 & 10170 & 053934.257 & -250853.44 & $\mathrm{ACV}$ & $8.11-8.14$ & $1.50125(3)$ & $2451914.64(3)$ & B9 $\mathrm{Si}$ & -0.054 & -0.243 \\
\hline HD 38366 & 10320 & 054532.682 & +091900.77 & $\mathrm{ACV}$ & $8.94-9.01$ & $0.625264(5)$ & $2454143.68(1)$ & B9 Si & +0.009 & +0.051 \\
\hline HD 38698 & 10400 & 054702.886 & -142826.75 & $\mathrm{ACV}$ & $9.09-9.12$ & $3.1643(2)$ & $2452690.64(6)$ & $\mathrm{A} 0 \mathrm{Si}$ & -0.003 & +0.011 \\
\hline HD 39635 & & 055325.382 & -104042.39 & ACV: & $8.75-8.82$ & $3.9660(2)$ & $2452752.51(8)$ & $\mathrm{A} 0(\mathrm{~V})$ & +0.078 & +0.382 \\
\hline HD 42382 & 11300 & 061030.681 & +032858.72 & $\mathrm{ACV}$ & $9.11-9.15$ & $5.9277(7)$ & $2452921.9(2)$ & B9 Cr Eu Si & +0.056 & -0.019 \\
\hline HD 42695 & 11420 & 061112.958 & -224941.46 & $\mathrm{ACV}$ & $8.12-8.14$ & $1.06877(2)$ & $2455148.78(3)$ & B9 Si & -0.035 & -0.015 \\
\hline HD 44038 & 11668 & 061910.142 & -092206.21 & $\mathrm{ACV}$ & $9.73-9.77$ & $0.689929(6)$ & $2453029.75(1)$ & $\mathrm{A} 0 \mathrm{Eu} \mathrm{Cr} \mathrm{Sr}$ & +0.033 & +0.014 \\
\hline HD 44290 & 11750 & 062028.159 & -141148.34 & $\mathrm{ACV}$ & $8.52-8.55$ & $1.71523(4)$ & $2452032.48(3)$ & B9 $\mathrm{Cr} \mathrm{Eu}$ & +0.026 & -0.031 \\
\hline HD 44456 & 11800 & 062155.420 & +001815.18 & $\mathrm{ACV}$ & $8.50-8.54$ & $3.8934(2)$ & $2452243.73(8)$ & $\mathrm{A} 0 \mathrm{Si} \mathrm{Sr}$ & +0.000 & -0.016 \\
\hline HD 291674 & 12200 & 062914.344 & +004257.01 & $\mathrm{ACV}$ & $9.75-9.78$ & $2.7305(2)$ & $2453457.57(8)$ & B9 Si & -0.005 & +0.067 \\
\hline HD 258583 & 12260 & 063022.290 & +083936.98 & $\mathrm{ACV}$ & $8.76-8.83$ & $10.312(1)$ & $2452671.6(2)$ & $\mathrm{A} 0 \mathrm{Si}$ & -0.012 & -0.048 \\
\hline HD 45931 & 12280 & 063027.489 & -002221.41 & $\mathrm{ACV}$ & $8.95-9.00$ & $1.92699(5)$ & $2452199.82(4)$ & A0 Si & +0.058 & -0.017 \\
\hline HD 46234 & 12370 & 063032.021 & -384510.22 & $\mathrm{ACV}$ & $9.28-9.31$ & $4.6936(4)$ & $2451924.6(1)$ & $\mathrm{A} 0 \mathrm{Si}$ & -0.105 & -0.052 \\
\hline HD 47026 & 12590 & 063358.822 & -480902.09 & $\mathrm{ACV}$ & $9.51-9.56$ & $1.28037(2)$ & $2452143.88(2)$ & B9 $\mathrm{Sr} \mathrm{Cr} \mathrm{Eu}$ & +0.014 & -0.006 \\
\hline HD 46739 & 12530 & 063417.350 & -200833.82 & $\mathrm{ACV}$ & $9.30-9.35$ & $1.11115(3)$ & $2453366.80(3)$ & $\mathrm{A} 0 \mathrm{Si}$ & +0.003 & -0.059 \\
\hline HD 47714 & 12810 & 063932.657 & -114151.64 & $\mathrm{ACV}$ & $7.91-7.96$ & $4.6953(4)$ & $2452249.7(2)$ & B8 Si & -0.032 & -0.025 \\
\hline HD 48729 & 13000 & 064238.478 & -433029.45 & $\mathrm{ACV}$ & $9.41-9.46$ & $1.89150(5)$ & $2452963.74(4)$ & $\mathrm{A} 0 \mathrm{Si}$ & -0.023 & -0.050 \\
\hline HD 263361 & 13070 & 064558.980 & +190943.21 & $\mathrm{ACV}$ & $9.14-9.22$ & $88.9(1)$ & $2452715.5(9)$ & B9 Si & +0.019 & -0.009 \\
\hline HD 263582 & 13110 & 064621.920 & +090610.22 & $\mathrm{ACV}$ & $9.64-9.72$ & $2.09183(6)$ & $2452740.48(4)$ & B9 Si & +0.205 & -0.002 \\
\hline HD 49686 & 13460 & 064758.134 & -361259.79 & $\mathrm{ACV}$ & $9.80-9.84$ & $3.9648(2)$ & $2451929.63(8)$ & $\mathrm{A} 0 \mathrm{Cr} \mathrm{Eu} \mathrm{Si}$ & +0.133 & +0.040 \\
\hline HD 49479 & 13380 & 064827.943 & -021149.30 & $\mathrm{ACV}$ & $9.34-9.40$ & $7.3878(7)$ & $2452255.7(1)$ & B9 Si & -0.021 & -0.024 \\
\hline HD 289186 & 13400 & 064843.944 & +013631.96 & $\mathrm{ACV}$ & $9.59-9.62$ & $1.65625(5)$ & $2452654.67(5)$ & B8 Si & -0.087 & -0.056 \\
\hline HD 50221 & 13750 & 065017.773 & -405519.66 & $\mathrm{ACV}$ & $8.85-8.88$ & $1.97442(5)$ & $2451938.64(4)$ & B9 $\mathrm{Si}$ & -0.073 & -0.022 \\
\hline HD 50540 & 13860 & 065236.429 & -262344.44 & $\mathrm{ACV}$ & $9.74-9.81$ & $1.55352(3)$ & $2451877.76(3)$ & B9 $\mathrm{Si} \mathrm{Sr}$ & -0.125 & -0.047 \\
\hline HD 50391 & 13787 & 065238.633 & -101036.79 & $\mathrm{ACV}$ & $9.22-9.25$ & $1.18285(3)$ & $2453405.66(3)$ & B9 Si & -0.042 & -0.009 \\
\hline HD 50461 & 13810 & 065307.993 & -074555.98 & $\mathrm{ACV}$ & $7.75-7.81$ & $0.89403(2)$ & $2453411.76(3)$ & B9 $\mathrm{Si} \mathrm{Cr}$ & -0.058 & -0.094 \\
\hline HD 50829 & 13970 & 065325.999 & $-31 \quad 1220.44$ & $\mathrm{ACV}$ & $9.18-9.27$ & $3.4144(1)$ & $2451935.54(7)$ & $\mathrm{A} 0 \mathrm{Si}$ & +0.089 & -0.071 \\
\hline HD 50855 & 13986 & 065354.676 & -255633.82 & $\mathrm{ACV}$ & $10.10-10.16$ & $2.23913(6)$ & $2452754.52(5)$ & B9 Si & +0.005 & -0.074 \\
\hline HD 50895 & 14010 & 065412.893 & -230621.93 & $\mathrm{ACV}$ & $9.64-9.70$ & $3.5902(2)$ & $2452911.85(7)$ & B9 Si & -0.030 & -0.070 \\
\hline HD 51088 & 14070 & 065454.049 & -244305.19 & $\mathrm{ACV}$ & $8.25-8.29$ & $1.65260(4)$ & $2453445.55(3)$ & $\mathrm{B} 8 \mathrm{Si}$ & -0.130 & -0.073 \\
\hline HD 51031 & 14060 & 065504.104 & -162945.29 & $\mathrm{ACV}$ & $9.49-9.57$ & $2.36431(9)$ & $2452987.76(5)$ & $\mathrm{B} 8 \mathrm{Si}$ & +0.128 & +0.145 \\
\hline HD 51203 & 14110 & 065509.834 & -300343.99 & $\mathrm{ACV}$ & $10.39-10.43$ & $6.6752(8)$ & $2453389.7(2)$ & $\mathrm{A} 2 \mathrm{Sr} \mathrm{Eu} \mathrm{Cr}$ & +0.484 & +0.069 \\
\hline HD 51307 & 14130 & 065619.949 & -125114.88 & $\mathrm{ACV}$ & $9.10-9.14$ & $4.017(2)$ & $2453759.63(8)$ & B8 Si & -0.037 & -0.058 \\
\hline HD 51172 & 14100 & 065622.803 & +031149.10 & $\mathrm{ACV}$ & $8.61-8.66$ & $2.47926(8)$ & $2453759.74(5)$ & B9 $\mathrm{Si}$ & -0.045 & -0.055 \\
\hline HD 51303 & 14128 & 065645.298 & -005503.48 & $\mathrm{ACV}$ & $9.33-9.36$ & $4.5076(3)$ & $2452925.86(9)$ & $\mathrm{A} 0 \mathrm{Si}$ & -0.089 & -0.018 \\
\hline HD 51426 & & 065655.264 & -105922.49 & ACV: & $8.56-8.59$ & $3.1064(1)$ & $2453466.54(6)$ & B6III & -0.120 & -0.119 \\
\hline HD 51790 & 14250 & 065751.162 & -215613.99 & $\mathrm{ACV}$ & $9.31-9.35$ & $0.96385(2)$ & $2454509.61(3)$ & B8 Si & -0.118 & -0.029 \\
\hline HD 52297 & 14360 & 065850.067 & -395918.60 & $\mathrm{ACV}$ & $9.19-9.22$ & $1.62773(4)$ & $2454847.80(3)$ & $\mathrm{A} 0 \mathrm{Si} \mathrm{Cr}$ & +0.061 & +0.030 \\
\hline HD 51912 & 14270 & 065901.706 & -042306.29 & $\mathrm{ACV}$ & $8.71-8.75$ & $1.56420(5)$ & $2453051.63(5)$ & $\mathrm{A} 0 \mathrm{Si}$ & -0.064 & -0.060 \\
\hline HD 52567 & & 070051.144 & -233547.82 & ACV: & $9.31-9.40$ & $11.9467(9)$ & $2455083.9(1)$ & B8 & -0.091 & -0.080 \\
\hline HD 52669 & 14440 & 070134.558 & -150306.70 & $\mathrm{ACV}$ & $9.10-9.14$ & $29.47(1)$ & $2455084.9(6)$ & $\mathrm{A} 0 \mathrm{Si}$ & -0.061 & -0.048 \\
\hline HD 52589 & 14400 & 070135.127 & -061842.93 & $\mathrm{ACV}$ & $8.06-8.09$ & $1.68418(6)$ & $2451905.69(5)$ & $\mathrm{B} 8 \mathrm{Si}$ & -0.099 & -0.013 \\
\hline HD 52693 & 14450 & 070154.005 & -092606.60 & $\mathrm{ACV}$ & $8.59-8.62$ & $2.44598(8)$ & $2455162.77(5)$ & $\mathrm{A} 0 \mathrm{Si}$ & -0.032 & -0.008 \\
\hline HD 53021 & 14570 & 070221.643 & -263154.14 & $\mathrm{ACV}$ & $9.93-9.98$ & $3.7544(2)$ & $2453159.46(7)$ & B9 Si & +0.000 & -0.030 \\
\hline HD 53067 & 14590 & 070230.703 & -273430.91 & $\mathrm{ACV}$ & $10.17-10.20$ & $3.2758(2)$ & $2452566.8(1)$ & B9 Si & -0.069 & -0.041 \\
\hline HD 53081 & 14600 & 070403.828 & +084107.38 & $\mathrm{ACV}$ & $9.69-9.72$ & $5.8727(7)$ & $2453087.6(2)$ & B9 Si & -0.083 & -0.094 \\
\hline HD 53204 & 14630 & 070416.227 & +013026.82 & $\mathrm{ACV}$ & $7.64-7.67$ & $2.28534(7)$ & $2454181.61(5)$ & B9 $\mathrm{Si}$ & -0.037 & -0.001 \\
\hline HD 53695 & 14747 & 070515.875 & -195115.20 & $\mathrm{ACV}$ & $9.19-9.23$ & $0.83891(2)$ & $2452202.78(2)$ & B8 Si & -0.113 & -0.063 \\
\hline HD 53851 & 14780 & 070627.659 & -030656.67 & $\mathrm{ACV}$ & $7.58-7.62$ & $2.02464(5)$ & $2452925.86(4)$ & B9 Si & -0.112 & -0.100 \\
\hline HD 54445 & 14930 & 070742.540 & -280253.87 & $\mathrm{ACV}$ & $8.69-8.73$ & $0.657375(6)$ & $2455118.83(1)$ & $\mathrm{A} 0 \mathrm{Si}$ & -0.033 & -0.050 \\
\hline HD 54544 & 14936 & 070852.215 & -111059.63 & $\mathrm{ACV}$ & $9.11-9.14$ & $2.22896(9)$ & $2453812.58(7)$ & B9 Si & -0.007 & +0.001 \\
\hline HD 54766 & 14956 & 070924.646 & -180724.01 & $\mathrm{ACV}$ & $9.85-9.90$ & $1.99280(5)$ & 2454531.60(4) & B9 Si & +0.043 & -0.001 \\
\hline HD 54962 & 15010 & 070958.456 & -242435.19 & $\mathrm{ACV}$ & $9.32-9.35$ & $2.5423(2)$ & $2454837.77(7)$ & $\mathrm{A} 0 \mathrm{Si}$ & -0.101 & -0.036 \\
\hline HD 56273 & 15300 & 071557.316 & -123235.31 & $\mathrm{ACV}$ & $7.91-7.95$ & $1.78661(4)$ & $2453653.86(4)$ & $\mathrm{B} 8 \mathrm{Si}$ & -0.061 & -0.056 \\
\hline HD 56748 & 15470 & 071726.752 & -202748.93 & $\mathrm{ACV}$ & $8.87-8.92$ & $5.9332(5)$ & $2452784.5(1)$ & A0 Si & -0.062 & -0.102 \\
\hline HD 56773 & 15475 & 071750.121 & -142006.95 & $\mathrm{ACV}$ & $9.32-9.38$ & $0.768298(8)$ & $2453759.74(1)$ & B8 Si & +0.026 & +0.017 \\
\hline HD 57040 & 15570 & 071642.240 & -532613.10 & $\mathrm{ACV}$ & $9.19-9.21$ & $26.952(9)$ & $2453634.8(5)$ & $\mathrm{A} 2 \mathrm{Eu} \mathrm{Sr}$ & +0.550 & +0.059 \\
\hline HD 57372 & 15680 & 072002.705 & -242457.50 & $\mathrm{ACV}$ & $7.90-7.93$ & $7.8880(8)$ & $2454973.5(1)$ & B8 Si & -0.132 & -0.210 \\
\hline HD 57946 & 15780 & 072153.243 & -363740.48 & $\mathrm{ACV}$ & $8.35-8.42$ & $2.15820(6)$ & $2451874.81(4)$ & $\mathrm{B} 8 \mathrm{Si}$ & -0.085 & -0.008 \\
\hline HD 58378 & 15940 & 072341.301 & -373709.82 & $\mathrm{ACV}$ & $9.81-9.83$ & $1.81823(6)$ & $2452171.86(5)$ & $\mathrm{B} 8 \mathrm{Si}$ & +0.002 & -0.040 \\
\hline HD 58151 & 15850 & 072345.378 & -163605.87 & $\mathrm{ACV}$ & $9.94-9.98$ & $2.53609(8)$ & $2452694.67(5)$ & $\mathrm{A} 0 \mathrm{Si}$ & +0.042 & +0.004 \\
\hline SAO 173716 & 16050 & 072555.546 & -262210.56 & $\mathrm{ACV}$ & $10.10-10.14$ & $2.48286(8)$ & $2453503.48(5)$ & B9 Si & -0.057 & -0.023 \\
\hline HD 58794 & 16054 & 072631.736 & -165856.47 & $\mathrm{ACV}$ & $10.56-10.61$ & $2.7999(1)$ & $2451869.78(5)$ & B9 Si & +0.062 & +0.008 \\
\hline HD 59164 & 16170 & 072741.771 & -261411.54 & $\mathrm{ACV}$ & $8.37-8.41$ & $4.3299(2)$ & $2451888.73(8)$ & $\mathrm{A} 2 \mathrm{Sr} \mathrm{Eu}$ & +0.057 & -0.008 \\
\hline HD 59574 & 16260 & 072904.126 & -352237.74 & $\mathrm{ACV}$ & $10.32-10.37$ & $1.60661(4)$ & $2453447.58(3)$ & $\mathrm{A} 0 \mathrm{Si}$ & -0.030 & -0.055 \\
\hline HD 59437 & 16250 & 072919.477 & -141830.20 & $\mathrm{ACV}$ & $9.25-9.29$ & $10.801(2)$ & $2454769.8(2)$ & $\mathrm{A} 0 \mathrm{Cr} \mathrm{Eu}$ & +0.104 & +0.015 \\
\hline HD 59379 & 16220 & 072934.938 & -053618.02 & $\mathrm{ACV}$ & $8.74-8.78$ & $1.02487(2)$ & $2454526.64(2)$ & B9 Si & -0.022 & -0.032 \\
\hline HD 59758 & 16330 & 072949.244 & -380438.47 & $\mathrm{ACV}$ & $10.62-10.65$ & $2.17004(9)$ & $2454889.76(6)$ & $\mathrm{A} 0 \mathrm{Si}$ & -0.014 & +0.076 \\
\hline HD 59716 & 16310 & 073014.872 & -262103.55 & $\mathrm{ACV}$ & $9.64-9.67$ & $4.3333(4)$ & $2454133.75(9)$ & B9 Si & -0.102 & -0.068 \\
\hline HD 59752 & 16327 & 073049.075 & -152537.98 & $\mathrm{ACV}$ & $9.29-9.37$ & $2.66700(9)$ & $2451963.57(5)$ & B9 Si & -0.036 & -0.074 \\
\hline HD 59982 & 16388 & 073207.443 & $-07 \quad 1525.42$ & $\mathrm{ACV}$ & $8.37-8.42$ & $5.1292(4)$ & $2451933.6(1)$ & $\mathrm{B} 8 \mathrm{Si}$ & -0.042 & -0.071 \\
\hline HD 59981 & 16387 & 073216.221 & -052901.24 & $\mathrm{ACV}$ & $9.82-9.85$ & 1.44561(3) & $2454509.74(3)$ & A0 Si & +0.023 & -0.042 \\
\hline HD 60908 & 16610 & 073408.258 & -514351.46 & $\mathrm{ACV}$ & $9.74-9.81$ & $1.54617(3)$ & $2452635.67(3)$ & $\mathrm{B} 8 \mathrm{Si}$ & -0.009 & +0.061 \\
\hline
\end{tabular}


Table A.1. continued.

\begin{tabular}{|c|c|c|c|c|c|c|c|c|c|c|}
\hline Star & ID (RM09) & $\alpha(\mathrm{J} 2000)$ & $\delta(\mathrm{J} 2000)$ & Type & $\begin{array}{c}\text { Range }(V) \\
{[\mathrm{mag}]}\end{array}$ & $\begin{array}{l}\text { Period } \\
\text { [d] }\end{array}$ & $\begin{array}{c}\text { Epoch (HJD) } \\
{[\mathrm{d}]}\end{array}$ & Spectral type & $\begin{array}{c}(B-V) \\
{[\mathrm{mag}]}\end{array}$ & $\begin{array}{c}\left(J-K_{\mathrm{s}}\right) \\
{[\mathrm{mag}]}\end{array}$ \\
\hline HD 61334 & 16790 & 073638.851 & -451629.10 & $\mathrm{ACV}$ & $9.17-9.20$ & $19.150(5)$ & $2452559.6(4)$ & $\mathrm{A} 2 \mathrm{Si} \mathrm{Cr}$ & +0.026 & +0.003 \\
\hline HD 61134 & & 073656.131 & -210309.52 & ACV: & $8.48-8.52$ & $4.6170(3)$ & $2451968.65(9)$ & B9 & -0.119 & -0.104 \\
\hline HD 61369 & 16820 & 073808.275 & -215355.32 & $\mathrm{ACV}$ & $9.67-9.69$ & $1.94372(5)$ & $2454216.55(4)$ & B9 Si & -0.035 & -0.063 \\
\hline HD 61368 & 16810 & 073819.477 & -141553.46 & $\mathrm{ACV}$ & $10.21-10.28$ & $1.82373(4)$ & $2452240.81(4)$ & A0 Si & +0.061 & -0.046 \\
\hline HD 61622 & 16900 & 073827.294 & -394134.36 & $\mathrm{ACV}$ & $8.52-8.56$ & $0.851946(9)$ & $2452188.84(2)$ & B9 $\mathrm{Si}$ & -0.038 & -0.090 \\
\hline HD 61490 & 16870 & 073846.869 & -214018.92 & $\mathrm{ACV}$ & $9.98-10.03$ & $1.31542(2)$ & $2454741.89(3)$ & $\mathrm{A} 0 \mathrm{Si}$ & -0.074 & -0.069 \\
\hline HD 61731 & 16940 & 073953.487 & -204410.92 & $\mathrm{ACV}$ & $9.86-9.91$ & $8.652(2)$ & $2453411.6(2)$ & $\mathrm{A} 0 \mathrm{Cr} \mathrm{Eu}$ & +0.215 & +0.020 \\
\hline CD-44 3656 & 17100 & 074126.031 & -445258.54 & $\mathrm{ACV}$ & $8.66-8.69$ & $1.06120(2)$ & $2454521.70(2)$ & $\mathrm{A} 0 \mathrm{Si}$ & +0.061 & +0.021 \\
\hline HD 62244 & 17060 & 074206.706 & -240654.19 & $\mathrm{ACV}$ & $8.16-8.19$ & $16.300(5)$ & $2453769.7(4)$ & $\mathrm{A} 2 \mathrm{Sr} \mathrm{Eu}$ & +0.097 & +0.004 \\
\hline HD 62446 & & 074233.297 & -361556.74 & ACV: & $9.22-9.28$ & $31.60(2)$ & $2452251.0(6)$ & A0 & +0.077 & -0.014 \\
\hline HD 62535 & 17160 & 074335.715 & -211653.74 & $\mathrm{ACV}$ & $8.02-8.07$ & $2.45123(8)$ & $2454622.49(5)$ & $\mathrm{A} 0 \mathrm{Si}$ & -0.003 & -0.057 \\
\hline HD 63204 & 17420 & 074336.953 & -632357.06 & $\mathrm{ACV}$ & $8.23-8.35$ & $1.83817(2)$ & $2451965.58(2)$ & B9 Si & -0.038 & -0.069 \\
\hline HD 62632 & 17210 & 074433.787 & -121849.38 & $\mathrm{ACV}$ & $8.54-8.57$ & $3.2801(2)$ & $2453048.66(9)$ & $\mathrm{A} 2 \mathrm{Cr} \mathrm{Eu}$ & -0.007 & -0.041 \\
\hline HD 63728 & 17550 & 074638.419 & -614354.29 & $\mathrm{ACV}$ & $9.31-9.36$ & $1.83993(4)$ & $2454870.64(4)$ & $\mathrm{A} 0 \mathrm{Eu} \mathrm{CrSi}$ & +0.071 & +0.020 \\
\hline HD 63304 & 17460 & 074713.226 & -263427.50 & $\mathrm{ACV}$ & $8.88-8.95$ & $1.31281(2)$ & $2451919.72(2)$ & B8 Si & -0.110 & -0.087 \\
\hline HD 64369 & 17670 & 075003.933 & -604001.56 & $\mathrm{ACV}$ & $8.79-8.82$ & $0.89113(1)$ & $2454105.68(2)$ & B9 $\mathrm{Si}$ & -0.034 & -0.020 \\
\hline HD 64288 & 17660 & 075057.256 & -481318.49 & $\mathrm{ACV}$ & $10.16-10.21$ & $1.28436(2)$ & $2453509.58(3)$ & B9 $\mathrm{Eu} \mathrm{Cr} \mathrm{Sr}$ & +0.043 & -0.010 \\
\hline HD 64901 & 17810 & 075422.055 & -405126.56 & $\mathrm{ACV}$ & $8.52-8.55$ & $4.0606(2)$ & $2452252.76(8)$ & $\mathrm{A} 0 \mathrm{Si}$ & -0.113 & -0.080 \\
\hline CPD-60 944A & 18010 & 075645.110 & -604854.29 & $\mathrm{ACV}$ & $7.63-7.65$ & $3.7367(3)$ & $2452654.7(1)$ & B9 Si & -0.009 & +0.006 \\
\hline HD 65570 & 17950 & 075806.687 & -311505.69 & $\mathrm{ACV}$ & $8.85-8.87$ & $1.770028(6)$ & $2452191.82(5)$ & $\mathrm{B} 8 \mathrm{Si}$ & -0.012 & -0.066 \\
\hline HD 65743 & 18000 & 075900.121 & -302025.06 & $\mathrm{ACV}$ & $9.11-9.16$ & $1.84372(4)$ & $2452944.81(4)$ & B9 Si & -0.003 & -0.046 \\
\hline HD 66821 & 18470 & 080227.503 & -551032.64 & $\mathrm{ACV}$ & $9.92-9.98$ & $154.9(3)$ & $2452928(2)$ & $\mathrm{A} 0 \mathrm{Si}$ & +0.049 & +0.084 \\
\hline HD 66766 & 18450 & 080243.107 & -503714.48 & $\mathrm{ACV}$ & $8.64-8.66$ & $1.60710(5)$ & $2453858.52(5)$ & B9 Si & -0.059 & -0.100 \\
\hline HD 66991 & 18490 & 080512.966 & -192354.56 & $\mathrm{ACV}$ & $8.55-8.57$ & $1.03660(2)$ & $2454574.59(3)$ & B9 Si & -0.021 & -0.064 \\
\hline HD 67217 & 18540 & 080538.593 & -335321.76 & $\mathrm{ACV}$ & $9.18-9.24$ & $2.43755(8)$ & $2453516.53(5)$ & A2 Si & -0.062 & -0.075 \\
\hline HD 67868 & 18710 & 080713.081 & -545546.23 & $\mathrm{ACV}$ & $9.20-9.23$ & $2.7584(1)$ & $2452667.74(5)$ & $\mathrm{A} 0 \mathrm{Si}$ & +0.135 & +0.089 \\
\hline HD 67951 & 18750 & 080823.598 & -454743.00 & $\mathrm{ACV}$ & $8.79-8.83$ & $1.15741(2)$ & $2454827.73(2)$ & B8 Si Cr & -0.031 & -0.035 \\
\hline HD 67982 & 18770 & 080830.938 & -450804.25 & $\mathrm{ACV}$ & $9.82-9.86$ & $1.11836(2)$ & $2454540.75(2)$ & B9 $\mathrm{Si}$ & -0.038 & -0.028 \\
\hline HD 68480 & 18970 & 080933.729 & -575909.37 & $\mathrm{ACV}$ & $8.85-8.90$ & $7.3327(7)$ & $2451950.6(1)$ & B9 $\mathrm{Eu} \mathrm{Sr} \mathrm{Si}$ & +0.121 & -0.013 \\
\hline HD 68476 & 18960 & 081032.723 & -460012.91 & $\mathrm{ACV}$ & $8.58-8.62$ & $0.839719(9)$ & $2453055.57(2)$ & B9 Si & -0.042 & -0.040 \\
\hline CPD-37 2043 & 19110 & 081259.773 & -375456.68 & $\mathrm{ACV}$ & $10.25-10.37$ & $6.2945(5)$ & $2453076.6(1)$ & B7 & +0.069 & +0.014 \\
\hline HD 69193 & 19170 & 081345.177 & -474623.36 & $\mathrm{ACV}$ & $10.20-10.22$ & $2.6937(2)$ & $2453406.80(8)$ & $\mathrm{A} 0 \mathrm{Si}$ & -0.089 & +0.010 \\
\hline HD 69544 & 19220 & 081511.813 & -502620.44 & $\mathrm{ACV}$ & $9.30-9.36$ & $236.5(7)$ & $2452810(3)$ & $\mathrm{B} 8 \mathrm{Si}$ & +0.132 & +0.041 \\
\hline HD 69825 & 19280 & 081619.037 & -515629.80 & $\mathrm{ACV}$ & $9.35-9.38$ & $3.3180(2)$ & $2451964.60(6)$ & $\mathrm{B} 8 \mathrm{Si}$ & +0.216 & +0.110 \\
\hline HD 69913 & 19300 & 081636.700 & -531250.17 & $\mathrm{ACV}$ & $8.14-8.22$ & $19.975(3)$ & $2451977.6(2)$ & B9 Si & +0.092 & +0.037 \\
\hline HD 69932 & 19310 & 081724.304 & -454122.34 & $\mathrm{ACV}$ & $9.99-10.02$ & $2.30525(7)$ & $2453711.84(4)$ & B9 Si & +0.014 & -0.068 \\
\hline HD 70045 & 19340 & 081753.304 & -470414.41 & $\mathrm{ACV}$ & $9.99-10.05$ & $5.3057(4)$ & $2451925.7(1)$ & $\mathrm{A} 0 \mathrm{Si}$ & +0.210 & +0.148 \\
\hline HD 70749 & 19520 & 082122.074 & -512320.84 & $\mathrm{ACV}$ & $8.19-8.22$ & $2.3581(1)$ & $2454091.73(7)$ & B8 Si & -0.026 & -0.056 \\
\hline HD 71860 & 19840 & 082731.181 & -493135.29 & $\mathrm{ACV}$ & $9.48-9.52$ & $8.634(1)$ & $2452900.8(2)$ & $\mathrm{A} 0 \mathrm{Si} \mathrm{Cr}$ & +0.035 & +0.046 \\
\hline HD 72140 & 19930 & 082920.802 & -465336.91 & $\mathrm{ACV}$ & $9.62-9.65$ & $0.539735(4)$ & $2454530.72(1)$ & B8 Si & -0.007 & +0.098 \\
\hline HD 72055 & 19900 & 083034.877 & -070927.26 & $\mathrm{ACV}$ & $8.10-8.13$ & $2.7088(1)$ & $2453057.63(5)$ & $\mathrm{B} 8 \mathrm{Si}$ & -0.121 & -0.071 \\
\hline CD-33 5120 & 20020 & 083109.775 & -341028.19 & $\mathrm{ACV}$ & $9.56-9.63$ & $5.6830(4)$ & $2451889.8(1)$ & $\mathrm{Si}$ & +0.000 & -0.019 \\
\hline HD 72801 & 20180 & 083241.049 & -501235.43 & $\mathrm{ACV}$ & $9.59-9.61$ & $3.0045(2)$ & $2454570.71(9)$ & B9 $\mathrm{Cr} \mathrm{Eu} \mathrm{Sr}$ & +0.186 & +0.127 \\
\hline HD 73063 & 20290 & 083410.118 & -493335.18 & $\mathrm{ACV}$ & $10.21-10.25$ & $2.3219(7)$ & $2452698.72(5)$ & B9 $\mathrm{Eu} \mathrm{Cr}$ & -0.005 & -0.055 \\
\hline HD 73009 & 20260 & 083412.377 & -444810.37 & $\mathrm{ACV}$ & $9.42-9.48$ & $0.85539(1)$ & $2453495.55(2)$ & B9 Si & -0.038 & -0.049 \\
\hline CD-51 3094 & 20330 & 083427.069 & -522513.78 & $\mathrm{ACV}$ & $10.02-10.09$ & $5.3059(4)$ & $2451994.6(1)$ & $\mathrm{Si}$ & +0.220 & +0.096 \\
\hline HD 73607 & 20430 & 083718.775 & -475925.52 & $\mathrm{ACV}$ & $9.44-9.48$ & $2.7421(1)$ & $2452033.50(5)$ & A0 Si Cr & +0.104 & +0.043 \\
\hline HD 73850 & 20580 & 083821.659 & -510817.77 & $\mathrm{ACV}$ & $9.05-9.07$ & $1.24912(2)$ & $2452083.45(2)$ & $\mathrm{A} 0 \mathrm{Sr} \mathrm{Cr} \mathrm{Eu}$ & +0.178 & +0.205 \\
\hline HD 73737 & 20560 & 083852.061 & -302315.24 & $\mathrm{ACV}$ & $8.31-8.36$ & $39.67(2)$ & $2451948.7(8)$ & B9 Si & +0.045 & -0.009 \\
\hline HD 74423 & & 084017.984 & -645016.84 & ACV: & $8.58-8.66$ & $0.79037(1)$ & $2452606.86(1)$ & A1V & +0.210 & +0.121 \\
\hline SAO 220259 & & 084020.656 & -460725.64 & ACV: & $9.13-9.20$ & $14.304(3)$ & $2453036.6(3)$ & A & +0.048 & +0.008 \\
\hline HD 74636 & 20870 & 084252.841 & -514004.82 & $\mathrm{ACV}$ & $9.22-9.25$ & $0.654778(8)$ & $2453666.84(2)$ & B9 Si & +0.052 & +0.023 \\
\hline HD 74672 & 20900 & 084422.994 & -283139.20 & $\mathrm{ACV}$ & $9.84-9.87$ & $4.5284(4)$ & $2452709.7(1)$ & $\mathrm{A} 2 \mathrm{Sr} \mathrm{Cr} \mathrm{Eu}$ & +0.290 & +0.077 \\
\hline HD 74821 & 20920 & 084511.336 & -313558.35 & $\mathrm{ACV}$ & $8.56-8.59$ & $2.9633(2)$ & $2452071.47(9)$ & B9 $\mathrm{Si}$ & -0.088 & -0.074 \\
\hline HD 75293 & 21080 & 084717.672 & -475105.91 & $\mathrm{ACV}$ & $9.27-9.32$ & $1.52246(3)$ & $2451950.65(3)$ & B9 Si & -0.023 & +0.042 \\
\hline HD 75323 & 21090 & 084807.301 & -351824.13 & $\mathrm{ACV}$ & $8.95-8.97$ & $12.625(3)$ & $2454626.5(4)$ & B9 Si & +0.043 & +0.013 \\
\hline HD 76504 & & 085015.995 & -753931.06 & ACV: & $8.53-8.60$ & $0.90289(1)$ & $2454385.84(2)$ & $\mathrm{B} 8 \mathrm{~V}$ & +0.026 & -0.048 \\
\hline HD 76283 & & 085301.981 & -512908.64 & ACV: & $8.74-8.76$ & $1.94729(7)$ & $2453773.64(6)$ & B9III & -0.064 & -0.042 \\
\hline HD 76439 & 21510 & 085424.638 & -452715.50 & $\mathrm{ACV}$ & $7.96-8.01$ & $1.47243(3)$ & $2454253.58(3)$ & B9 Si & -0.133 & -0.102 \\
\hline HD 76590 & 21590 & 085457.701 & -521640.60 & $\mathrm{ACV}$ & $9.76-9.78$ & $2.6275(1)$ & $2453462.66(5)$ & B9 $\mathrm{Si}$ & +0.037 & -0.037 \\
\hline HD 76650 & 21610 & 085546.970 & -465204.23 & $\mathrm{ACV}$ & $8.43-8.48$ & $1.98314(5)$ & $2453016.77(4)$ & B9 Si & -0.097 & -0.072 \\
\hline BD-21 2641 & 21570 & 085550.572 & -220656.33 & $\mathrm{ACV}$ & $10.60-10.70$ & $2.28946(7)$ & 2452763.59(4) & $\mathrm{Si}$ & +0.015 & -0.007 \\
\hline HD 77013 & & 085934.002 & -055209.54 & ACV: & $9.24-9.28$ & $0.411738(2)$ & $2453787.700(8)$ & A3 & +0.323 & +0.157 \\
\hline HD 77885 & 22050 & 090151.720 & -644803.28 & $\mathrm{ACV}$ & $9.25-9.28$ & $0.94555(1)$ & $2453086.64(2)$ & B9 Si & +0.038 & +0.020 \\
\hline HD 77689 & 21980 & 090152.386 & -525411.44 & $\mathrm{ACV}$ & $8.44-8.49$ & $8.5955(9)$ & $2453850.3(2)$ & B9 Si & -0.108 & -0.137 \\
\hline HD 78201 & 22150 & 090552.462 & -343204.58 & $\mathrm{ACV}$ & $8.08-8.10$ & $1.55917(3)$ & $2451907.73(3)$ & $\mathrm{A} 0 \mathrm{Sr} \mathrm{Eu}$ & -0.040 & -0.065 \\
\hline HD 78568 & 22260 & 090622.415 & -591223.21 & $\mathrm{ACV}$ & $7.81-7.87$ & $3.2038(1)$ & $2451887.71(6)$ & B9 Si & -0.067 & -0.052 \\
\hline HD 78651 & 22290 & 090735.301 & -500431.75 & $\mathrm{ACV}$ & $10.44-10.49$ & $23.916(7)$ & $2454881.6(4)$ & $\mathrm{A} 0 \mathrm{Eu} \mathrm{Cr} \mathrm{Sr}$ & +0.430 & +0.039 \\
\hline HD 78942 & 22390 & 090940.753 & -413603.53 & $\mathrm{ACV}$ & $10.37-10.42$ & $24.184(7)$ & $2454485.7(5)$ & $\mathrm{A} 0 \mathrm{Si}$ & +0.158 & -0.046 \\
\hline HD 79606 & 22620 & 091150.501 & -651132.56 & $\mathrm{ACV}$ & $8.13-8.17$ & $2.09269(6)$ & $2452185.75(4)$ & B9 Si & +0.002 & -0.017 \\
\hline HD 79794 & 22690 & 091346.305 & -562440.45 & $\mathrm{ACV}$ & $9.25-9.28$ & $1.49881(4)$ & $2453529.60(4)$ & $\mathrm{A} \mathrm{Si}$ & +0.005 & -0.073 \\
\hline HD 79976 & 22750 & 091641.845 & -165013.14 & $\mathrm{ACV}$ & $8.54-8.56$ & $1.42619(4)$ & 2453768.78(4) & B9 $\mathrm{Sr} \mathrm{Cr} \mathrm{Eu}$ & +0.066 & -0.041 \\
\hline HD 80485 & 22880 & 091750.509 & -570911.52 & $\mathrm{ACV}$ & $9.69-9.79$ & $2.50216(8)$ & $2451959.63(5)$ & $\mathrm{A} 0 \mathrm{Si}$ & +0.005 & +0.000 \\
\hline HD 81349 & 23120 & 092322.371 & -493534.17 & $\mathrm{ACV}$ & $9.81-9.86$ & $0.588859(4)$ & $2454641.50(1)$ & A0 Si & +0.016 & +0.013 \\
\hline HD 81289 & 23080 & 092325.544 & -433604.86 & $\mathrm{ACV}$ & $8.38-8.45$ & $1.85811(4)$ & $2451977.62(4)$ & $\mathrm{A} 2 \mathrm{Eu} \mathrm{Sr} \mathrm{Cr}$ & +0.008 & -0.074 \\
\hline HD 81877 & 23270 & 092710.676 & -402205.24 & $\mathrm{ACV}$ & $8.82-8.89$ & $3.2151(2)$ & $2453175.49(6)$ & B9 $\mathrm{Eu} \mathrm{Cr} \mathrm{Sr}$ & +0.103 & -0.041 \\
\hline HD 82154 & 23360 & 092800.347 & -583034.27 & $\mathrm{ACV}$ & $8.63-8.68$ & $4.6199(3)$ & $2454089.79(9)$ & B9 Si & +0.057 & -0.078 \\
\hline HD 82691 & & 093259.080 & -234809.98 & ACV: & $8.36-8.42$ & $19.807(5)$ & $2452201.0(4)$ & A0 & +0.141 & +0.044 \\
\hline
\end{tabular}


Table A.1. continued.

\begin{tabular}{|c|c|c|c|c|c|c|c|c|c|c|}
\hline Star & ID (RM09) & $\alpha(\mathrm{J} 2000)$ & $\delta(\mathbf{J} 2000)$ & Type & $\begin{array}{c}\text { Range }(V) \\
{[\mathrm{mag}]}\end{array}$ & $\begin{array}{l}\text { Period } \\
\text { [d] }\end{array}$ & $\begin{array}{c}\text { Epoch (HJD) } \\
{[\mathrm{d}]}\end{array}$ & Spectral type & $\begin{array}{c}(B-V) \\
{[\mathrm{mag}]}\end{array}$ & $\begin{array}{c}\left(J-K_{\mathrm{s}}\right) \\
{[\mathrm{mag}]}\end{array}$ \\
\hline HD 82917 & 23620 & 093325.835 & -480413.34 & $\mathrm{ACV}$ & $9.73-9.76$ & $2.2460(1)$ & $2453861.60(4)$ & A2 Si & -0.051 & -0.045 \\
\hline HD 83002 & 23670 & 093336.434 & -532039.35 & $\mathrm{ACV}$ & $9.05-9.09$ & $1.55104(3)$ & $2454259.56(3)$ & B8 Si & -0.073 & -0.091 \\
\hline HD 82944 & 23630 & 093444.056 & -123625.50 & $\mathrm{ACV}$ & $8.64-8.67$ & $2.47906(8)$ & $2454959.59(5)$ & $\mathrm{A} 0 \mathrm{Sr} \mathrm{Eu}$ & +0.258 & -0.008 \\
\hline HD 83467 & 23800 & 093627.087 & -574219.04 & $\mathrm{ACV}$ & $9.68-9.73$ & $7.1905(6)$ & $2451941.6(1)$ & B9 Si & -0.005 & +0.004 \\
\hline HD 84001 & & 093927.473 & -631518.12 & ACV: & $7.76-7.79$ & $0.540937(5)$ & $2454231.57(1)$ & B8/B9V & -0.015 & -0.033 \\
\hline HD 84448 & & 094356.612 & -480628.79 & $\mathrm{ACV}:$ & $8.35-8.40$ & $1.01297(1)$ & $2453061.59(2)$ & $\mathrm{A} 2 \mathrm{~V}$ & +0.174 & +0.067 \\
\hline HD 84690 & 24170 & 094454.637 & -575833.69 & $\mathrm{ACV}$ & $9.50-9.56$ & $8.1212(8)$ & $2454152.7(2)$ & B8 Si & +0.188 & +0.594 \\
\hline HD 84656 & 24160 & 094456.937 & -560102.69 & $\mathrm{ACV}$ & $8.17-8.20$ & $2.46916(8)$ & $2451979.60(5)$ & B8 Si & -0.104 & -0.106 \\
\hline HD 84642 & & 094516.742 & -482203.24 & ACV: & $9.38-9.44$ & $6.4051(5)$ & $2453759.7(1)$ & B9IV/V & +0.007 & -0.020 \\
\hline HD 84865 & 24200 & 094538.448 & -630349.65 & $\mathrm{ACV}$ & $9.99-10.02$ & $2.09091(8)$ & $2453528.54(6)$ & $\mathrm{A} 0 \mathrm{Si}$ & +0.031 & -0.032 \\
\hline HD 85469 & & 094953.693 & -584834.37 & ACV: & $7.54-7.58$ & $2.4305(1)$ & $2453064.60(7)$ & B8/B9III & -0.100 & -0.068 \\
\hline HD 85629 & & 095012.810 & -664428.57 & ACV: & $8.59-8.65$ & $1.72016(4)$ & $2452752.57(3)$ & B9III/IV & -0.012 & -0.035 \\
\hline HD 85453 & 24400 & 095022.064 & -502008.29 & $\mathrm{ACV}$ & $8.19-8.22$ & $1.71392(6)$ & $2451934.54(5)$ & B9 Si & -0.075 & -0.046 \\
\hline HD 85767 & 24470 & 095214.034 & -565938.69 & $\mathrm{ACV}$ & $9.50-9.60$ & $7.2793(7)$ & $2451945.7(1)$ & $\mathrm{B} 8 \mathrm{Si}$ & +0.134 & +0.044 \\
\hline HD 85873 & 24500 & 095225.051 & -624559.56 & $\mathrm{ACV}$ & $9.37-9.39$ & $3.7521(2)$ & $2452212.82(7)$ & $\mathrm{A} 2 \mathrm{Si}$ & +0.038 & +0.014 \\
\hline HD 304810 & 24600 & 095434.712 & -612431.86 & $\mathrm{ACV}$ & $9.91-9.95$ & $2.43247(8)$ & $2454150.81(5)$ & A0 Si & +0.017 & +0.031 \\
\hline HD 86253 & 24680 & 095511.800 & -601246.97 & $\mathrm{ACV}$ & $10.06-10.13$ & $0.613366(5)$ & $2451907.78(1)$ & $\mathrm{A} 0 \mathrm{Si}$ & +0.097 & -0.042 \\
\hline HD 87528 & & 100318.248 & -633107.42 & $\mathrm{ACV}:$ & $9.71-9.78$ & $50.35(3)$ & $2452212.8(9)$ & B8/9III & +0.002 & +0.035 \\
\hline HD 87881 & 25170 & 100603.478 & -594410.35 & $\mathrm{ACV}$ & $9.83-9.88$ & $1.454632(3)$ & $2453802.62(3)$ & $\mathrm{A} 0 \mathrm{Si}$ & -0.068 & +0.011 \\
\hline HD 88042 & 25200 & 100726.637 & -553109.90 & $\mathrm{ACV}$ & $10.09-10.16$ & $6.9977(6)$ & $2452691.7(1)$ & Ap Eu Sr: Cr: & +0.099 & +0.079 \\
\hline HD 88343 & & 100913.920 & -610511.96 & ACV: & $9.49-9.56$ & $22.085(6)$ & $2454181.8(4)$ & B8/B9III/IV & -0.052 & +0.001 \\
\hline HD 88385 & 25310 & 100949.446 & -564453.25 & $\mathrm{ACV}$ & $8.07-8.11$ & $6.5098(6)$ & $2451919.7(1)$ & $\mathrm{A} 0 \mathrm{Cr} \mathrm{Eu} \mathrm{Si}$ & +0.054 & -0.017 \\
\hline HD 88485 & 25330 & 101005.874 & -634617.35 & $\mathrm{ACV}$ & $9.29-9.36$ & $8.0093(8)$ & $2454205.7(1)$ & $\mathrm{A} 2 \mathrm{Si}$ & +0.052 & +0.041 \\
\hline HD 88488 & & 101214.804 & -011538.37 & ACV: & $8.61-8.67$ & $0.86158(1)$ & $2453146.55(2)$ & A3 & +0.280 & +0.161 \\
\hline HD 88757 & 25410 & 101243.653 & -554701.78 & $\mathrm{ACV}$ & $8.97-9.01$ & $6.1274(5)$ & $2454254.6(1)$ & $\mathrm{B} 8 \mathrm{Si}$ & -0.045 & -0.018 \\
\hline HD 89519 & 25720 & 101717.795 & -680835.29 & $\mathrm{ACV}$ & $8.31-8.35$ & $2.6099(2)$ & $2452811.57(7)$ & B9 $\mathrm{Eu} \mathrm{Cr} \mathrm{Sr}$ & +0.019 & -0.020 \\
\hline HD 299070 & & 101931.394 & -543000.80 & ACV: & $9.43-9.48$ & $6.3385(5)$ & $2452707.7(1)$ & B8 & +0.073 & +0.055 \\
\hline HD 89726 & & 101938.601 & -581143.58 & $\mathrm{ACV}:$ & $9.66-9.71$ & $5.5420(4)$ & $2452703.7(1)$ & B9 & -0.045 & -0.026 \\
\hline HD 90730 & 26040 & 102709.534 & -571109.94 & $\mathrm{ACV}$ & $8.85-8.87$ & $1.89746(7)$ & $2454111.82(5)$ & A0 Si & -0.089 & -0.084 \\
\hline HD 307699 & 26090 & 102736.226 & -620957.73 & $\mathrm{ACV}$ & $10.02-10.07$ & $5.1869(5)$ & $2454772.8(1)$ & $\mathrm{A} 2 \mathrm{Si}$ & +0.107 & +0.037 \\
\hline HD 91087 & 26190 & 103034.789 & -223115.87 & $\mathrm{ACV}$ & $9.48-9.50$ & $7.709(1)$ & $2454926.7(2)$ & $\mathrm{A} 0 \mathrm{Sr} \mathrm{Eu} \mathrm{Cr}$ & +0.238 & +0.005 \\
\hline HD 91735 & 26370 & 103232.435 & -740429.69 & $\mathrm{ACV}$ & $9.49-9.52$ & $9.775(1)$ & $2454629.5(2)$ & $\mathrm{A} 0 \mathrm{Eu} \mathrm{Sr}$ & +0.384 & +0.151 \\
\hline HD 300860 & 26420 & 103533.368 & -564240.36 & $\mathrm{ACV}$ & $10.08-10.16$ & $2.59009(8)$ & $2453411.81(5)$ & $\mathrm{A} 2 \mathrm{Si}$ & +0.077 & -0.123 \\
\hline HD 92190 & & 103721.800 & -591048.52 & $\mathrm{ACV}$ & $8.51-8.59$ & $1.24067(2)$ & $2454230.64(2)$ & B8 Vp He Mn Si & -0.049 & -0.069 \\
\hline HD 92286 & 26520 & 103815.130 & -543952.23 & $\mathrm{ACV}$ & $9.70-9.81$ & $13.916(3)$ & $2452697.7(3)$ & $\mathrm{A} 0 \mathrm{Eu} \mathrm{Cr}$ & +0.177 & +0.025 \\
\hline HD 92379 & 26610 & 103852.294 & -533610.18 & $\mathrm{ACV}$ & $7.94-7.97$ & $1.63373(4)$ & $2454441.79(3)$ & B8 Si & -0.075 & -0.058 \\
\hline HD 92849 & 26820 & 104210.065 & -533032.73 & $\mathrm{ACV}$ & $8.85-8.90$ & $2.7103(1)$ & $2452944.84(5)$ & B8 Si & -0.066 & -0.076 \\
\hline HD 305451 & 26844 & 104236.368 & -600234.77 & $\mathrm{ACV}$ & $10.06-10.10$ & $8.156(1)$ & $2453870.7(2)$ & B9 Si & +0.047 & -0.033 \\
\hline HD 93821 & 27150 & 104850.147 & -552133.93 & $\mathrm{ACV}$ & $7.93-7.96$ & $5.8350(4)$ & $2451964.3(1)$ & B9 Si & -0.084 & -0.085 \\
\hline HD 94111 & 27210 & 105046.053 & -555543.81 & $\mathrm{ACV}$ & $9.70-9.73$ & $1.22088(3)$ & $2453129.73(4)$ & $\mathrm{A} 2 \mathrm{Cr} \mathrm{Sr} \mathrm{Eu}$ & +0.208 & +0.044 \\
\hline HD 94873 & 27350 & 105614.584 & -523551.19 & $\mathrm{ACV}$ & $8.30-8.34$ & $1.81730(4)$ & $2452820.60(4)$ & B8 Si & -0.089 & -0.050 \\
\hline HD 95974 & 27630 & 110158.008 & -760309.36 & $\mathrm{ACV}$ & $8.66-8.73$ & $5.5160(4)$ & $2455010.5(1)$ & A0 Si & +0.202 & +0.102 \\
\hline HD 95987 & 27640 & 110330.282 & -542506.86 & $\mathrm{ACV}$ & $9.36-9.40$ & $1.52651(5)$ & $2454974.53(5)$ & B9 $\mathrm{Si}$ & -0.028 & -0.010 \\
\hline HD 96910 & 27960 & 110858.104 & -482410.30 & $\mathrm{ACV}$ & $8.07-8.13$ & $13.383(3)$ & $2451965.7(3)$ & B9 $\mathrm{Si} \mathrm{Cr} \mathrm{Eu}$ & +0.071 & +0.001 \\
\hline HD 97655 & & 111326.117 & -583005.10 & $\mathrm{ACV}$ & $9.17-9.26$ & $5.3714(4)$ & $2452030.6(1)$ & A0IV/Vp: & +0.052 & -0.026 \\
\hline HD 98486 & 28370 & 111815.537 & -741025.44 & $\mathrm{ACV}$ & $8.61-8.63$ & $1.61400(4)$ & $2454968.55(3)$ & B9 $\mathrm{Si}$ & +0.111 & -0.014 \\
\hline HD 99204 & 28570 & 112421.336 & -591709.69 & $\mathrm{ACV}$ & $8.86-8.93$ & $1.71767(4)$ & $2453701.84(3)$ & B9 Si & -0.048 & -0.029 \\
\hline SAO 222874 & 28920 & 113416.010 & -410916.89 & $\mathrm{ACV}$ & $7.35-7.39$ & $4.1202(2)$ & $2453849.63(8)$ & $\mathrm{A} 0 \mathrm{Eu} \mathrm{Sr} \mathrm{Cr}$ & +0.023 & +0.055 \\
\hline HD 100956 & 29050 & 113632.618 & -623721.15 & $\mathrm{ACV}$ & $9.55-9.58$ & $2.3799(1)$ & $2454566.67(7)$ & B9 Si & +0.148 & +0.167 \\
\hline HD 102659 & 29620 & 114847.613 & -644343.90 & $\mathrm{ACV}$ & $9.66-9.69$ & $2.16336(9)$ & $2453054.80(6)$ & A2 $\mathrm{Si}$ & +0.102 & +0.061 \\
\hline HD 103303 & 29790 & 115338.001 & -551823.72 & $\mathrm{ACV}$ & $9.78-9.83$ & $1.56519(3)$ & $2453902.49(3)$ & $\mathrm{A} 0 \mathrm{Si}$ & -0.035 & +0.009 \\
\hline CD-50 6498 & 29950 & 115628.330 & -510816.07 & $\mathrm{ACV}$ & $10.43-10.48$ & $2.14648(6)$ & $2453886.67(4)$ & B9 Si & +0.080 & -0.024 \\
\hline HD 103844 & 29990 & 115711.933 & -763445.53 & $\mathrm{ACV}$ & $10.30-10.40$ & $52.95(4)$ & $2452234.8(9)$ & $\mathrm{A} 0 \mathrm{Si}$ & +0.207 & +0.047 \\
\hline HD 104044 & 30060 & 115853.088 & -432255.92 & $\mathrm{ACV}$ & $9.58-9.60$ & $3.0492(2)$ & $2452635.81(9)$ & $\mathrm{A} 0 \mathrm{Sr} \mathrm{Eu}$ & +0.002 & +0.078 \\
\hline HD 104314 & 30180 & 120042.852 & -620120.44 & $\mathrm{ACV}$ & $9.86-9.93$ & $4.6150(3)$ & $2451938.73(9)$ & $\mathrm{A} 0 \mathrm{Si}$ & -0.009 & -0.022 \\
\hline HD 104376 & 30200 & 120104.643 & -634245.73 & $\mathrm{ACV}$ & $9.73-9.79$ & $4.9399(3)$ & $2453073.8(1)$ & $\mathrm{B} 8 \mathrm{Si}$ & -0.017 & +0.025 \\
\hline HD 105457 & 30490 & 120833.730 & -622208.15 & $\mathrm{ACV}$ & $8.97-9.04$ & $1.73772(4)$ & $2452234.84(4)$ & A0 Si & +0.071 & +0.010 \\
\hline HD 106688 & 30900 & 121619.917 & -584631.57 & $\mathrm{ACV}$ & $9.31-9.40$ & $2.64328(9)$ & $2451980.70(5)$ & B6 Si & +0.010 & -0.075 \\
\hline HD 109789 & 31840 & 123759.169 & -580124.49 & $\mathrm{ACV}$ & $9.69-9.75$ & $2.7934(1)$ & $2452145.47(6)$ & B9 Si & +0.017 & +0.008 \\
\hline CPD-73 1028 & 32160 & 124437.541 & -743015.57 & $\mathrm{ACV}$ & $9.41-9.46$ & $0.740810(7)$ & $2452794.53(2)$ & A8 Sr & +0.491 & +0.237 \\
\hline HD 111055 & 32280 & 124718.537 & -633258.50 & ACV: & $9.92-9.96$ & $1.01506(2)$ & $2452674.83(3)$ & A4- & +0.553 & +0.225 \\
\hline HD 112528 & 32730 & 125735.316 & -194501.68 & $\mathrm{ACV}$ & $8.24-8.28$ & $5.7829(6)$ & $2451963.8(1)$ & $\mathrm{A} 3 \mathrm{Sr} \mathrm{Eu} \mathrm{Cr}$ & +0.338 & +0.131 \\
\hline HD 114696 & 33160 & 131251.150 & -480943.62 & $\mathrm{ACV}$ & $9.65-9.71$ & $3.5620(2)$ & $2452071.54(7)$ & $\mathrm{A} 0 \mathrm{Si}$ & -0.064 & -0.092 \\
\hline HD 115789 & 33480 & 132037.177 & -583855.85 & $\mathrm{ACV}$ & $9.18-9.22$ & $2.12060(6)$ & $2452083.62(4)$ & B9 Si & +0.143 & +0.022 \\
\hline HD 116864 & & 132800.218 & -631329.25 & ACV: & $9.03-9.07$ & $2.6726(1)$ & $2451979.72(5)$ & B9II/III & +0.019 & -0.004 \\
\hline HD 117537 & 33900 & 133210.583 & -560226.78 & $\mathrm{ACV}$ & $9.48-9.55$ & $6.1706(5)$ & $2452443.5(1)$ & B9 $\mathrm{Si}$ & +0.081 & +0.024 \\
\hline HD 117855 & & 133438.095 & -631107.32 & ACV: & $9.52-9.60$ & $26.63(1)$ & $2453158.7(5)$ & B9 & -0.028 & -0.048 \\
\hline HD 118502 & 34230 & 133851.231 & -584707.35 & $\mathrm{ACV}$ & $9.80-9.86$ & $1.82389(4)$ & $2455002.56(4)$ & B9 Si & -0.096 & -0.027 \\
\hline HD 119343 & & 134442.230 & -635633.52 & ACV: & $9.21-9.29$ & $3.2699(2)$ & $2453597.53(6)$ & B8/B9II/III & -0.007 & +0.020 \\
\hline HD 119716 & 34530 & 134557.119 & -493937.53 & $\mathrm{ACV}$ & $9.22-9.24$ & $4.5132(4)$ & $2453054.8(1)$ & B9 Si & -0.030 & -0.021 \\
\hline HD 121081 & 34830 & 135400.943 & -280833.21 & $\mathrm{ACV}$ & $8.41-8.45$ & $3.4542(2)$ & $2452025.61(7)$ & $\mathrm{A} 0 \mathrm{Si}$ & +0.052 & -0.066 \\
\hline HD 123627 & 35410 & 141201.283 & -701030.80 & $\mathrm{ACV}$ & $8.18-8.20$ & $4.3916(3)$ & $2452173.49(8)$ & $\mathrm{A} 3 \mathrm{Sr} \mathrm{Eu} \mathrm{Cr}$ & +0.248 & +0.092 \\
\hline HD 123927 & & 141250.261 & -633054.57 & ACV: & $8.83-8.86$ & $5.7795(4)$ & $2453981.3(1)$ & B9III & +0.136 & -0.017 \\
\hline TYC $8690-1870-1$ & & 141804.625 & -585917.55 & ACV: & $11.45-11.56$ & $4.9176(3)$ & $2453836.7(1)$ & B8 & +0.199 & +0.063 \\
\hline HD 125903 & 35930 & 142724.399 & -755348.38 & $\mathrm{ACV}$ & $9.41-9.46$ & $1.56465(3)$ & $2452070.54(3)$ & $\mathrm{A} 0 \mathrm{Si}$ & -0.045 & -0.016 \\
\hline HD 128521 & 36540 & 143936.394 & -581028.98 & $\mathrm{ACV}$ & $9.37-9.41$ & $4.0258(3)$ & $2451996.7(1)$ & B9 Si & +0.045 & -0.004 \\
\hline HD 128840 & 36690 & 144126.472 & -574122.77 & $\mathrm{ACV}$ & $9.10-9.16$ & $1.92510(5)$ & $2452129.47(2)$ & B9 Si & +0.049 & +0.093 \\
\hline HD 129751 & 37010 & 144759.665 & -684217.32 & $\mathrm{ACV}$ & $9.36-9.44$ & $1.38971(3)$ & $2451966.85(3)$ & $\mathrm{B} 8 \mathrm{Si}$ & -0.013 & +0.007 \\
\hline HD 130336 & 37120 & 145052.981 & -663122.27 & $\mathrm{ACV}$ & $8.86-8.92$ & $1.29476(2)$ & $2452725.73(3)$ & $\mathrm{B} 8 \mathrm{Si}$ & -0.017 & -0.046 \\
\hline HD 130423 & 37140 & 145101.547 & -632941.77 & $\mathrm{ACV}$ & $9.60-9.68$ & $1.21067(2)$ & $2453168.76(2)$ & B9 Si & +0.123 & +0.046 \\
\hline
\end{tabular}


Table A.1. continued.

\begin{tabular}{|c|c|c|c|c|c|c|c|c|c|c|}
\hline Star & ID (RM09) & $\alpha(\mathrm{J} 2000)$ & $\delta(\mathrm{J} 2000)$ & Type & $\begin{array}{l}\text { Range }(V) \\
{[\mathrm{mag}]}\end{array}$ & $\begin{array}{l}\text { Period } \\
\text { [d] }\end{array}$ & $\begin{array}{c}\text { Epoch (HJD) } \\
{[\mathrm{d}]}\end{array}$ & Spectral type & $\begin{array}{c}(B-V) \\
{[\mathrm{mag}]}\end{array}$ & $\begin{array}{c}\left(J-K_{\mathrm{s}}\right) \\
{[\mathrm{mag}]}\end{array}$ \\
\hline HD 132988 & 37760 & 150524.700 & -650527.92 & $\mathrm{ACV}$ & $10.17-10.24$ & $2.56368(8)$ & $2452548.50(5)$ & $\mathrm{A} 0 \mathrm{Si}$ & +0.114 & +0.047 \\
\hline HD 133722 & 37930 & 150749.229 & -510839.37 & $\mathrm{ACV}$ & $9.67-9.73$ & $2.08809(6)$ & $2452081.56(4)$ & $\mathrm{B} 8 \mathrm{Si}$ & +0.024 & +0.015 \\
\hline HD 133702 & 37910 & 151107.558 & -730818.19 & $\mathrm{ACV}$ & $9.48-9.54$ & $2.10997(6)$ & $2452102.49(4)$ & B8 Si & -0.069 & -0.066 \\
\hline HD 134348 & 38140 & 151314.868 & -672243.63 & $\mathrm{ACV}$ & $9.14-9.19$ & $1.22525(2)$ & $2452791.52(2)$ & B9 Si & -0.050 & -0.008 \\
\hline HD 135800 & 38610 & 151909.289 & -520401.46 & $\mathrm{ACV}$ & $10.08-10.12$ & $6.2881(5)$ & $2453624.5(1)$ & B9 Si & -0.007 & -0.014 \\
\hline HD 136150 & 38730 & 152050.357 & -473142.29 & $\mathrm{ACV}$ & $9.89-9.93$ & $2.5568(2)$ & $2454269.73(7)$ & B9 Si & +0.085 & +0.014 \\
\hline HD 138151 & 39330 & 153240.717 & -545539.65 & $\mathrm{ACV}$ & $9.28-9.35$ & $5.0419(3)$ & 2451939.8(1) & B8 Si & +0.092 & -0.010 \\
\hline HD 138519 & 39440 & 153526.763 & -572502.30 & $\mathrm{ACV}$ & $7.90-7.97$ & $12.340(2)$ & $2451936.9(2)$ & B8 Si & +0.042 & +0.030 \\
\hline HD 138773 & 39520 & 153734.445 & -624053.12 & $\mathrm{ACV}$ & $7.66-7.70$ & $3.7911(2)$ & $2452651.86(7)$ & $\mathrm{A} 0 \mathrm{Si}$ & +0.104 & +0.023 \\
\hline HD 139472 & 39690 & 154159.713 & -641759.54 & $\mathrm{ACV}$ & $8.61-8.68$ & $1.79206(4)$ & 2452489.51(4) & B9 Si & -0.052 & +0.019 \\
\hline CPD-63 3687 & 40030 & 154959.485 & -640720.64 & $\mathrm{ACV}$ & $10.39-10.43$ & $0.96591(2)$ & $2454901.89(3)$ & $\mathrm{Si}$ & +0.038 & -0.012 \\
\hline HD 143383 & 40600 & 160220.452 & -495808.81 & $\mathrm{ACV}$ & $10.19-10.23$ & $5.1227(5)$ & 2451984.8(1) & B9 Si & +0.242 & +0.059 \\
\hline HD 143868 & 40750 & 160529.244 & -550228.44 & $\mathrm{ACV}$ & $9.69-9.75$ & $2.08514(6)$ & $2451954.82(4)$ & B9 Si & +0.154 & +0.059 \\
\hline HD 144059 & 40810 & 160831.999 & -671920.05 & $\mathrm{ACV}$ & $9.03-9.09$ & $22.213(2)$ & 2452094.6(4) & $\mathrm{A} 0 \mathrm{Si}$ & -0.054 & -0.053 \\
\hline CD-54 6496 & 40942 & 160834.028 & -542835.76 & ACV: & $10.22-10.29$ & $1.05816(2)$ & 2451955.83(2) & A3- & +0.697 & +0.280 \\
\hline HD 144815 & & 161023.831 & -532610.07 & ACV: & $9.18-9.24$ & $3.4101(2)$ & $2453112.72(7)$ & B8 & -0.055 & -0.064 \\
\hline HD 146269 & 41370 & 161817.460 & -553018.76 & $\mathrm{ACV}$ & $9.98-10.04$ & $1.63076(4)$ & $2452667.86(3)$ & B9 Si & +0.035 & -0.013 \\
\hline HD 146555 & 41410 & 161959.349 & -575428.27 & $\mathrm{ACV}$ & $10.27-10.33$ & $1.72941(4)$ & $2452658.84(3)$ & B9 Si & -0.028 & -0.012 \\
\hline HD 147346 & 41620 & 162409.435 & -541613.34 & $\mathrm{ACV}$ & $9.73-9.78$ & $2.64214(9)$ & $2451965.78(5)$ & B9 Si & +0.055 & -0.036 \\
\hline HD 147876 & 41700 & 162652.927 & -503544.38 & $\mathrm{ACV}$ & $9.96-10.01$ & $1.02872(2)$ & $2452031.72(3)$ & $\mathrm{A} 0 \mathrm{Si}$ & +0.045 & +0.033 \\
\hline HD 148848 & 42060 & 163242.100 & -410204.59 & $\mathrm{ACV}$ & $7.43-7.50$ & $8.343(1)$ & 2453068.8(1) & A0 $\mathrm{Si} \mathrm{Cr} \mathrm{Sr}$ & +0.211 & +0.066 \\
\hline HD 148955 & 42090 & 163411.894 & -513101.91 & $\mathrm{ACV}$ & $8.66-8.74$ & $4.8651(3)$ & $2451954.8(1)$ & B9 Si & -0.009 & -0.050 \\
\hline HD 149636 & 42320 & 163729.314 & -343204.72 & $\mathrm{ACV}$ & $10.10-10.17$ & $3.0215(1)$ & $2453178.59(6)$ & A0 Si & +0.183 & +0.008 \\
\hline HD 149831 & 42400 & 163916.442 & -445323.01 & $\mathrm{ACV}$ & $8.44-8.46$ & $3.3778(2)$ & $2452473.51(7)$ & B9 Si & +0.007 & -0.012 \\
\hline HD 149766 & 42370 & 163926.590 & -515449.58 & $\mathrm{ACV}$ & $9.49-9.59$ & $87.3(1)$ & 2452461(1) & B8 Si & +0.042 & -0.024 \\
\hline HD 150529 & 42600 & 164310.286 & -353950.64 & $\mathrm{ACV}$ & $8.45-8.51$ & $28.33(1)$ & $2452057.6(6)$ & $\mathrm{A} 0 \mathrm{Si}$ & +0.366 & +0.228 \\
\hline HD 150499 & 42570 & 164323.224 & -432805.45 & $\mathrm{ACV}$ & $9.58-9.63$ & $2.63063(9)$ & 2452115.52(5) & B9 Si & +0.047 & +0.076 \\
\hline HD 151610 & 42910 & 165030.844 & -451345.11 & $\mathrm{ACV}$ & $9.62-9.73$ & $2.43714(8)$ & $2452543.47(5)$ & A0 Si & +0.007 & +0.070 \\
\hline HD 151569 & 42890 & 165141.532 & -594427.25 & $\mathrm{ACV}$ & $9.46-9.51$ & $4.5320(3)$ & $2451964.81(9)$ & $\mathrm{A} 0 \mathrm{Si} \mathrm{Cr}$ & +0.038 & -0.003 \\
\hline HD 152771 & 43250 & 165816.551 & -535514.51 & $\mathrm{ACV}$ & $8.16-8.21$ & $2.19229(6)$ & 2451983.90(4) & $\mathrm{A} 0 \mathrm{Si}$ & -0.040 & -0.044 \\
\hline HD 153153 & 43320 & 165857.206 & -305314.59 & $\mathrm{ACV}$ & $9.50-9.61$ & $2.19198(6)$ & $2452703.85(4)$ & B9 Si & +0.036 & +0.023 \\
\hline HD 153192 & 43340 & 165905.517 & -270455.19 & $\mathrm{ACV}$ & $9.96-10.04$ & $11.357(2)$ & $2452102.6(2)$ & $\mathrm{A} 2 \mathrm{Eu} \mathrm{Cr}$ & +0.066 & +0.016 \\
\hline HD 153218 & 43360 & 165934.581 & -344923.72 & $\mathrm{ACV}$ & $9.91-10.02$ & $1.90185(5)$ & $2452086.60(4)$ & B9 Si & +0.041 & +0.059 \\
\hline HD 153735 & 43410 & 170324.696 & -473159.87 & $\mathrm{ACV}$ & $9.22-9.25$ & $5.7250(6)$ & $2452739.8(2)$ & $\mathrm{B} 8 \mathrm{Si}$ & +0.111 & +0.058 \\
\hline HD 154645 & 43690 & 170840.214 & -424141.02 & $\mathrm{ACV}$ & $9.01-9.05$ & $2.62214(9)$ & $2452115.54(5)$ & B9 Eu Sr Cr & +0.066 & +0.063 \\
\hline HD 155313 & 43860 & 171215.524 & -335704.42 & $\mathrm{ACV}$ & $10.24-10.31$ & $2.26531(7)$ & 2451994.77(4) & $\mathrm{A} 0 \mathrm{Si}$ & +0.002 & +0.050 \\
\hline HD 157063 & 44170 & 172312.723 & -444729.37 & $\mathrm{ACV}$ & $8.53-8.56$ & $4.7281(4)$ & $2452158.7(1)$ & $\mathrm{B} 8 \mathrm{Si}$ & +0.082 & +0.065 \\
\hline HD 157644 & 44260 & 172606.297 & -373635.20 & $\mathrm{ACV}$ & $8.35-8.39$ & 4.4097(3) & $2452032.73(9)$ & B9 Si & +0.068 & +0.029 \\
\hline HD 157650 & 44270 & 172644.583 & -470459.73 & $\mathrm{ACV}$ & $10.10-10.20$ & $1.34808(2)$ & $2452104.58(3)$ & B9 Si & +0.026 & +0.104 \\
\hline HD 157678 & 44280 & 172859.478 & -632526.16 & $\mathrm{ACV}$ & $8.12-8.16$ & $0.90781(1)$ & $2452008.74(2)$ & $\mathrm{B} 9 \mathrm{Si}$ & -0.087 & -0.078 \\
\hline HD 158336 & 44560 & 172926.705 & -183951.20 & $\mathrm{ACV}$ & $9.36-9.42$ & $1.76009(4)$ & $2452131.51(3)$ & B9 Si & +0.154 & +0.075 \\
\hline HD 158160 & 44470 & 173007.824 & -483649.38 & $\mathrm{ACV}$ & $9.43-9.50$ & $2.28312(7)$ & $2452008.73(5)$ & $\mathrm{A} 0 \mathrm{Si} \mathrm{Cr}$ & +0.014 & +0.004 \\
\hline HD 158596 & 44630 & 173103.462 & -212907.10 & $\mathrm{ACV}$ & $8.95-8.99$ & $2.02206(5)$ & $2451953.88(4)$ & B9 Si & +0.278 & +0.138 \\
\hline HD 158919 & 44713 & 173148.111 & +015034.56 & $\mathrm{ACV}$ & $9.21-9.28$ & $75.72(7)$ & 2452705(1) & A0 Si & +0.102 & +0.003 \\
\hline HD 315873 & 44680 & 173225.174 & -275619.69 & $\mathrm{ACV}$ & $10.47-10.52$ & $5.2766(5)$ & $2452129.5(1)$ & $\mathrm{B} 8 \mathrm{Si}$ & +0.349 & +0.237 \\
\hline HD 159898 & 45010 & 173854.896 & -384321.23 & $\mathrm{ACV}$ & $10.52-10.56$ & $4.7967(3)$ & $2452085.6(1)$ & A0 Si & +0.108 & -0.012 \\
\hline HD 160731 & 45280 & 174256.367 & -314321.41 & $\mathrm{ACV}$ & $9.45-9.51$ & $1.46489(3)$ & $2452787.85(3)$ & A0 Si & +0.063 & +0.056 \\
\hline HD 160711 & 45250 & 174304.180 & -361554.27 & $\mathrm{ACV}$ & $10.03-10.10$ & $1.06735(2)$ & $2452465.62(2)$ & $\mathrm{A} 0 \mathrm{Si}$ & +0.187 & -0.009 \\
\hline HD 160857 & 45310 & 174429.894 & -443848.65 & $\mathrm{ACV}$ & $10.01-10.12$ & $6.7125(6)$ & $2453472.8(1)$ & B9 Si & -0.039 & +0.017 \\
\hline HD 161168 & 45390 & 174507.375 & -272737.21 & $\mathrm{ACV}$ & $9.37-9.42$ & $1.53995(4)$ & $2452702.88(6)$ & $\mathrm{A} 0 \mathrm{Si}$ & +0.135 & +0.060 \\
\hline HD 161349 & 45470 & 174740.205 & -492432.38 & $\mathrm{ACV}$ & $8.45-8.52$ & 4.0194(2) & $2452115.57(8)$ & B9 Si & -0.043 & +0.005 \\
\hline HD 162108 & 45740 & 175155.058 & -492134.87 & $\mathrm{ACV}$ & $8.80-8.83$ & $0.78797(1)$ & $2452494.56(2)$ & B9 Si & +0.031 & -0.002 \\
\hline HD 162727 & 46000 & 175417.890 & -393744.29 & $\mathrm{ACV}$ & $8.91-8.95$ & $1.42068(3)$ & 2453113.81(3) & A0 Si & -0.052 & -0.035 \\
\hline HD 164053 & 46380 & 180204.586 & -501046.35 & $\mathrm{ACV}$ & $9.11-9.16$ & $2.9513(1)$ & 2452117.57(6) & B9 Si & -0.036 & +0.005 \\
\hline HD 164560 & 46505 & 180226.031 & -165836.60 & $\mathrm{ACV}$ & $9.50-9.56$ & $10.154(1)$ & $2452143.5(2)$ & A0 Si & +0.340 & +0.162 \\
\hline HD 166417 & & 181110.695 & -155341.67 & ACV: & $8.09-8.13$ & $2.2874(1)$ & $2452492.76(5)$ & B8 & +0.021 & +0.038 \\
\hline HD 166198 & & 181120.519 & -401825.41 & ACV: & $8.18-8.24$ & $5.7636(4)$ & $2452191.5(1)$ & B8IIIp & -0.111 & -0.083 \\
\hline HD 168507 & 47230 & 182125.564 & -311347.34 & $\mathrm{ACV}$ & $9.62-9.66$ & $2.8466(2)$ & $2452145.54(8)$ & $\mathrm{A} 0 \mathrm{Si}$ & +0.036 & +0.010 \\
\hline HD 169005 & & 182202.309 & +143927.82 & ACV: & $8.28-8.34$ & $1.10061(2)$ & $2454290.70(2)$ & A2 & -0.026 & -0.065 \\
\hline HD 172330 & 48290 & 184038.892 & -240605.83 & $\mathrm{ACV}$ & $9.60-9.66$ & $1.27535(2)$ & $2452117.59(2)$ & B9 Si & +0.088 & -0.002 \\
\hline HD 172703 & 48390 & 184306.940 & -332936.72 & $\mathrm{ACV}$ & $8.76-8.86$ & $19.478(5)$ & $2452810.9(4)$ & B9 $\mathrm{Eu} \mathrm{Sr} \mathrm{Cr}$ & +0.059 & -0.090 \\
\hline HD 342867 & 48560 & 184351.201 & +240452.34 & $\mathrm{ACV}$ & $9.35-9.38$ & $5.3182(6)$ & $2454292.6(1)$ & $\mathrm{A} 1 \mathrm{Si} \mathrm{Cr}$ & -0.001 & -0.022 \\
\hline HD 174646 & 48910 & 185137.930 & -010239.95 & $\mathrm{ACV}$ & $8.23-8.27$ & $1.18070(3)$ & $2453253.6(2)$ & B9 Si & +0.090 & +0.003 \\
\hline HD 175909 & 49110 & 185830.924 & -223945.51 & $\mathrm{ACV}$ & $9.09-9.13$ & $1.29948(2)$ & $2452085.68(3)$ & B9 Si & +0.092 & +0.040 \\
\hline HD 177338 & 49460 & 190448.178 & -135044.25 & $\mathrm{ACV}$ & $9.54-9.58$ & $3.0349(1)$ & $2452026.77(6)$ & B9 Si & +0.261 & +0.029 \\
\hline HD 177548 & & 190453.094 & +082834.60 & $\mathrm{ACV}:$ & $8.53-8.54$ & $0.93511(2)$ & 2453665.54(3) & A0 & +0.335 & +0.089 \\
\hline HD 178929 & 49744 & 191119.253 & -202050.09 & $\mathrm{ACV}$ & $7.70-7.77$ & $3.3453(2)$ & $2452552.50(7)$ & B8 Si Sr & -0.030 & -0.004 \\
\hline HD 180029 & 49955 & 191445.838 & +043712.17 & $\mathrm{ACV}$ & $8.01-8.03$ & $3.2858(2)$ & $2452877.6(1)$ & $\mathrm{A} 2 \mathrm{Si}$ & +0.126 & +0.038 \\
\hline HD 180153 & 50030 & 191654.545 & -360217.60 & $\mathrm{ACV}$ & $8.90-8.96$ & $2.01606(6)$ & $2452964.51(4)$ & B9 Si & -0.043 & -0.057 \\
\hline HD 180626 & 50115 & 191742.628 & -130218.75 & $\mathrm{ACV}$ & $9.45-9.51$ & $2.28860(7)$ & $2451998.84(4)$ & B8 Si & +0.031 & -0.011 \\
\hline HD 181550 & 50290 & 192301.767 & -461320.27 & ACV & $8.66-8.69$ & $2.45177(8)$ & $2452540.64(5)$ & B9 $\mathrm{Si} \mathrm{Cr}$ & -0.019 & -0.049 \\
\hline HD 182340 & 50410 & 192423.151 & -052547.04 & $\mathrm{ACV}$ & $9.63-9.67$ & $2.8138(1)$ & $2452105.65(6)$ & $\mathrm{A} 0 \mathrm{Si}$ & +0.169 & +0.062 \\
\hline HD 187128 & 51570 & 194739.759 & +155427.47 & $\mathrm{ACV}$ & $7.63-7.66$ & $6.1858(7)$ & $2452904.6(2)$ & B9 Si Sr & +0.039 & -0.039 \\
\hline HD 189184 & & 195823.553 & +130424.91 & $\mathrm{ACV}$ : & $9.36-9.44$ & $1.17911(2)$ & $2454722.66(2)$ & B9 & +0.014 & -0.014 \\
\hline HD 189963 & 52700 & 200259.382 & -062551.28 & $\mathrm{ACV}$ & $10.02-10.05$ & $10.231(2)$ & $2452053.8(3)$ & A0 $\mathrm{Sr} \mathrm{Cr} \mathrm{Eu}$ & +0.330 & +0.124 \\
\hline HD 190075 & 52750 & 200313.233 & +004202.02 & $\mathrm{ACV}$ & $8.76-8.78$ & $1.66102(6)$ & $2453273.54(5)$ & $\mathrm{A} 0 \mathrm{Si}$ & +0.068 & -0.059 \\
\hline HD 196691 & 54900 & 203910.636 & -060927.35 & $\mathrm{ACV}$ & $8.58-8.62$ & $4.0428(2)$ & $2452490.65(8)$ & $\mathrm{A} 0 \mathrm{Si}$ & -0.040 & -0.026 \\
\hline HD 206028 & 57370 & 213845.773 & +242353.39 & $\mathrm{ACV}$ & $8.13-8.18$ & $0.785856(8)$ & 2452813.03(1) & $\mathrm{A} 0 \mathrm{Si}$ & -0.092 & -0.109 \\
\hline HD 216116 & 59720 & 225211.871 & -715310.14 & $\mathrm{ACV}$ & $9.21-9.25$ & $4.1275(3)$ & $2452116.7(1)$ & B9 Si & -0.082 & -0.065 \\
\hline
\end{tabular}


K. Bernhard et al.: A search for photometric variability in mCP stars using ASAS-3 data

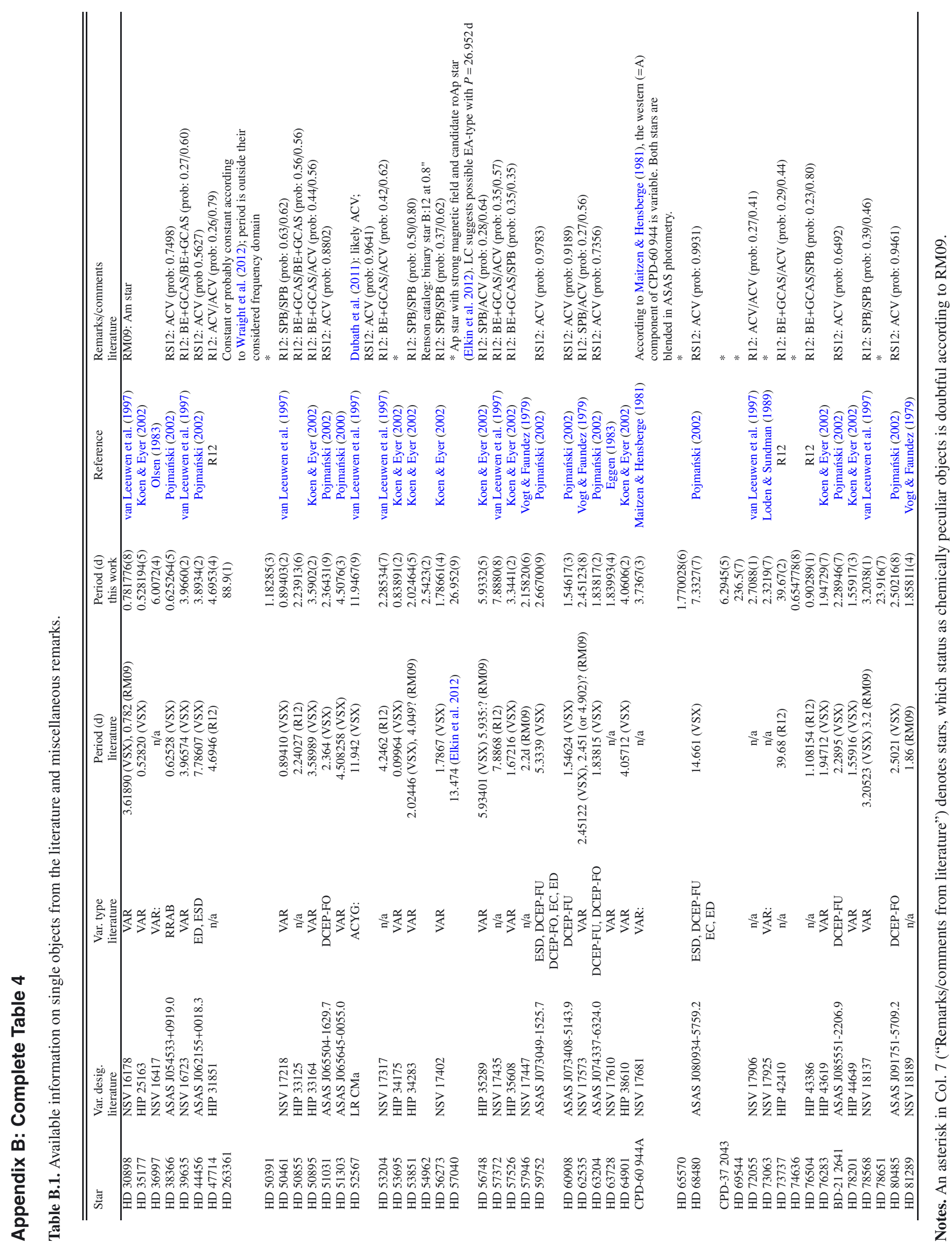


A\&A 581, A138 (2015)

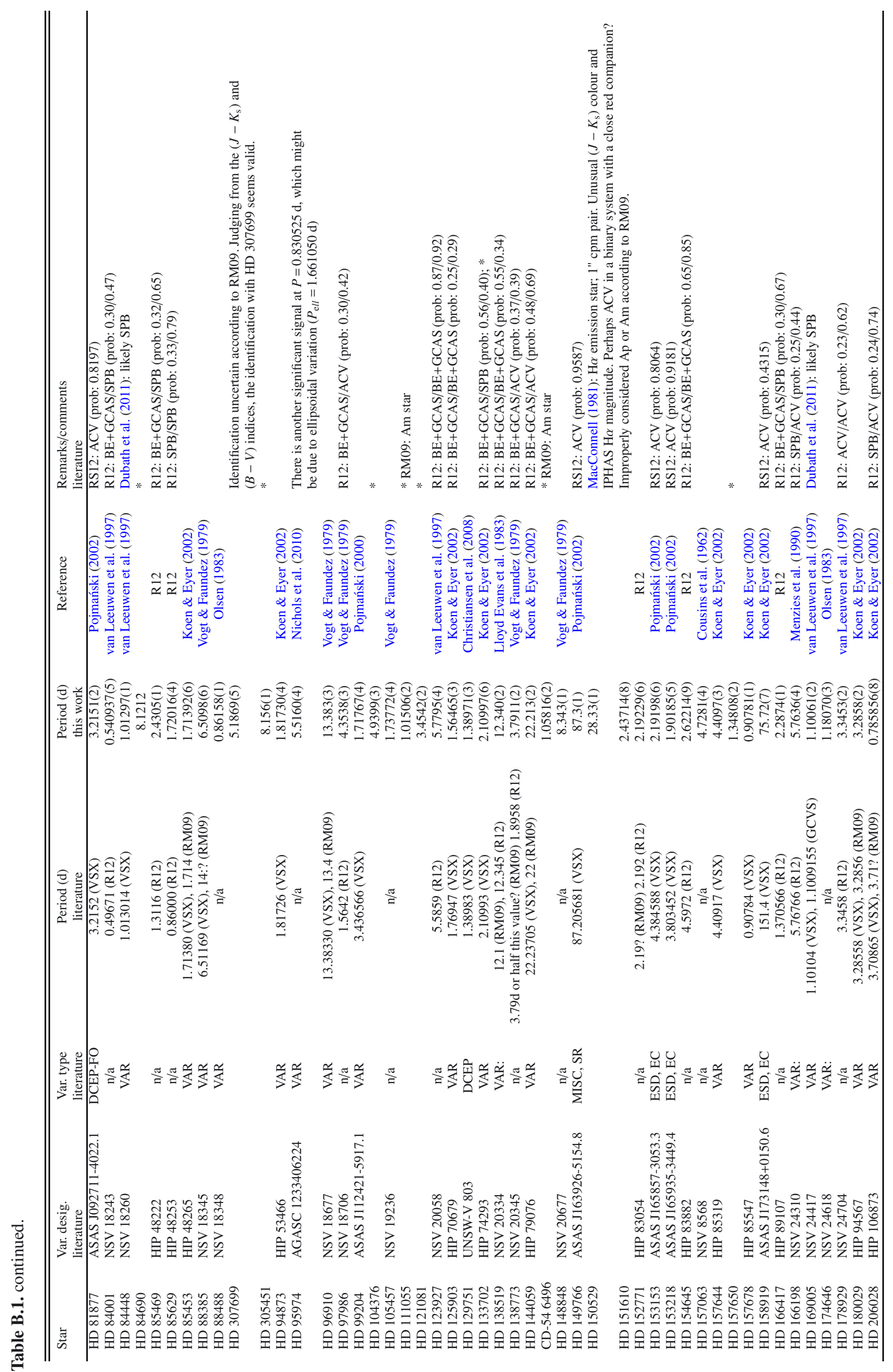


Appendix C: Light curves
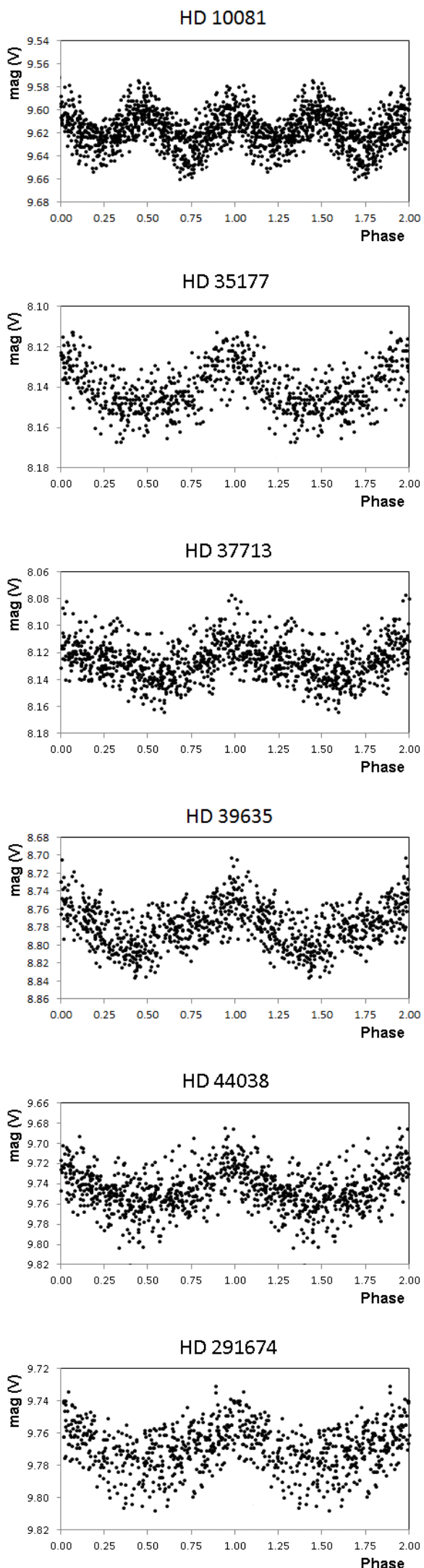


Fig. C.1. The light curves of all objects, folded with the period listed in Tables 2 and 3, respectively. 

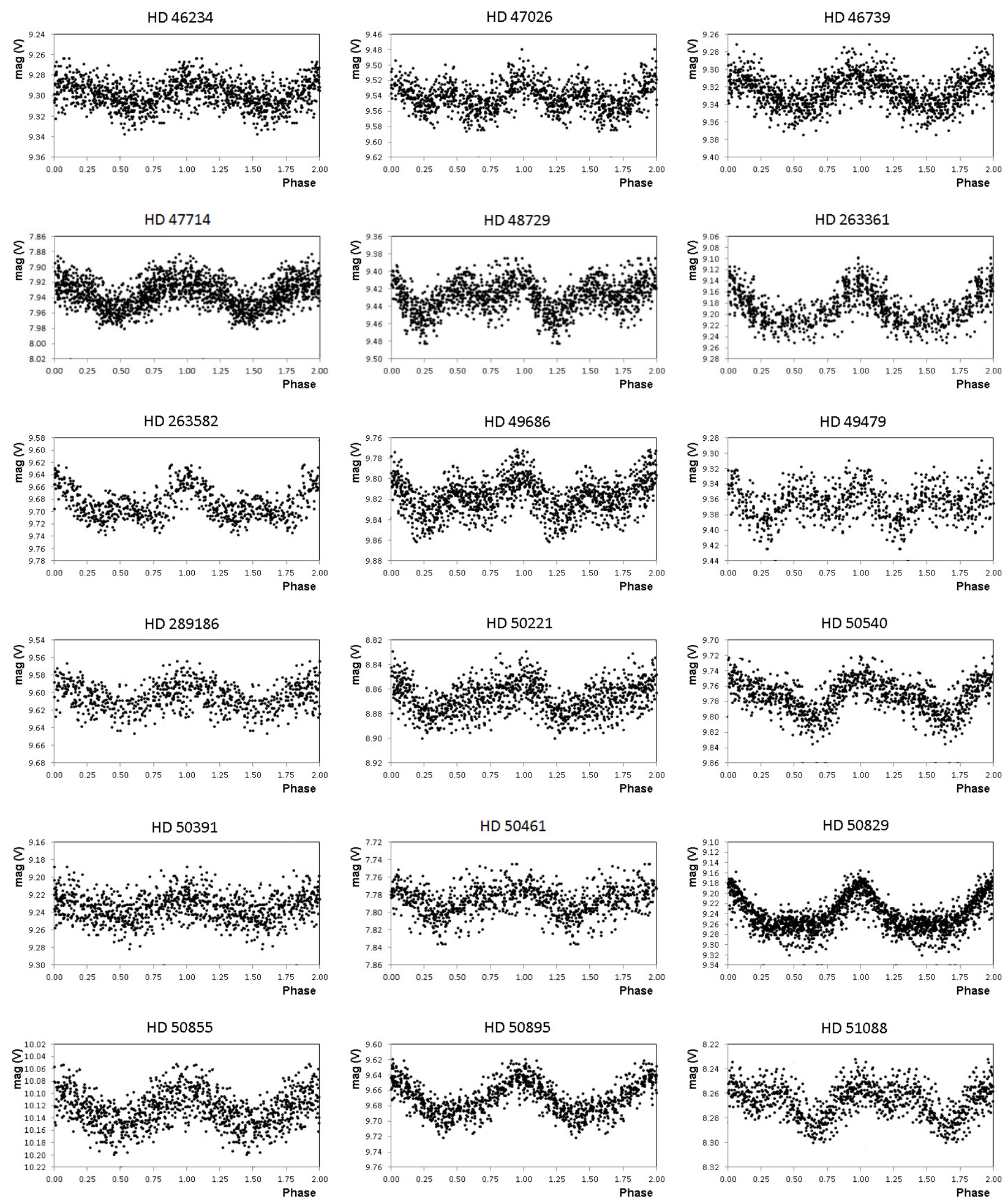

Fig. C.1. continued. 

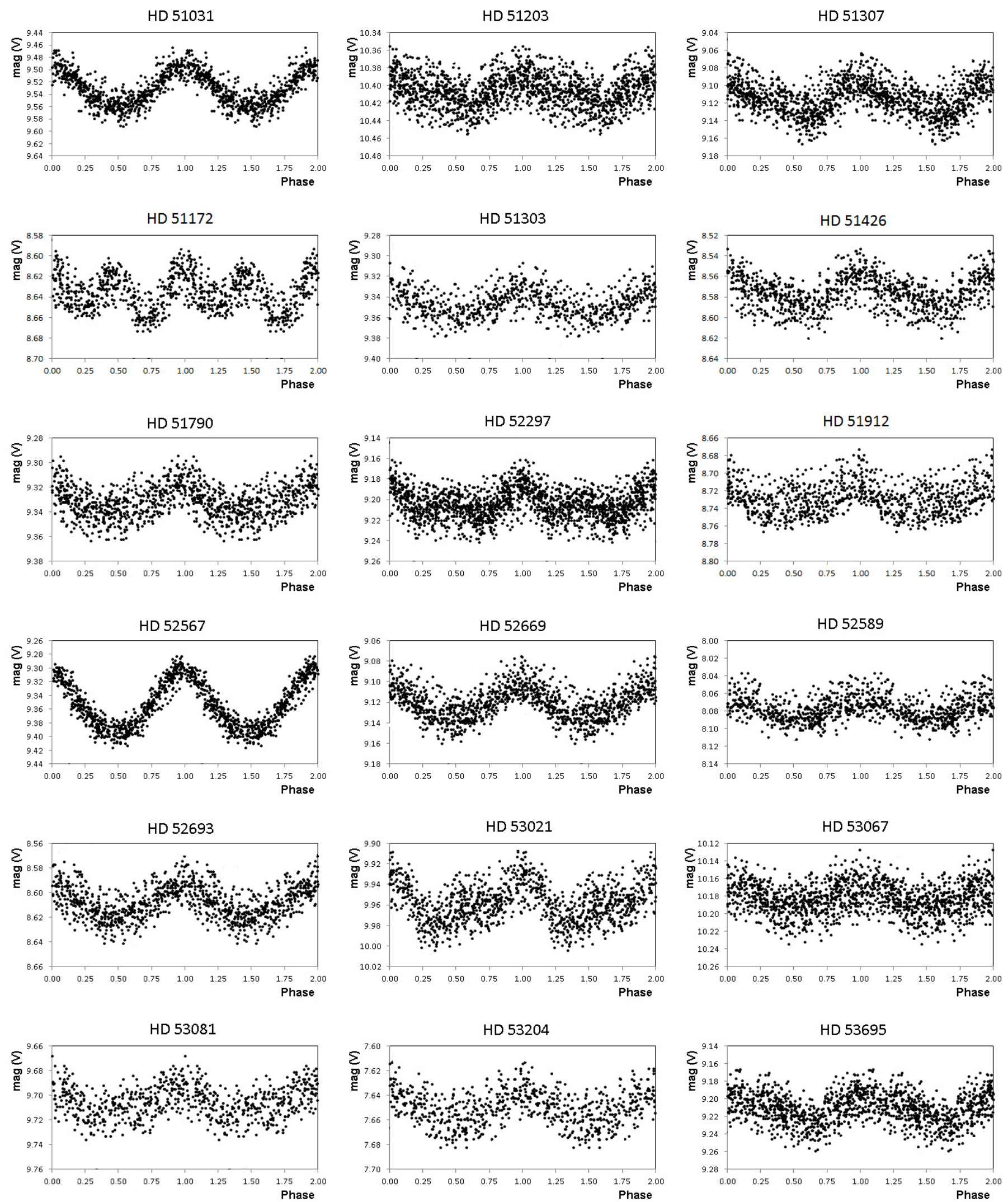

Fig. C.1. continued. 

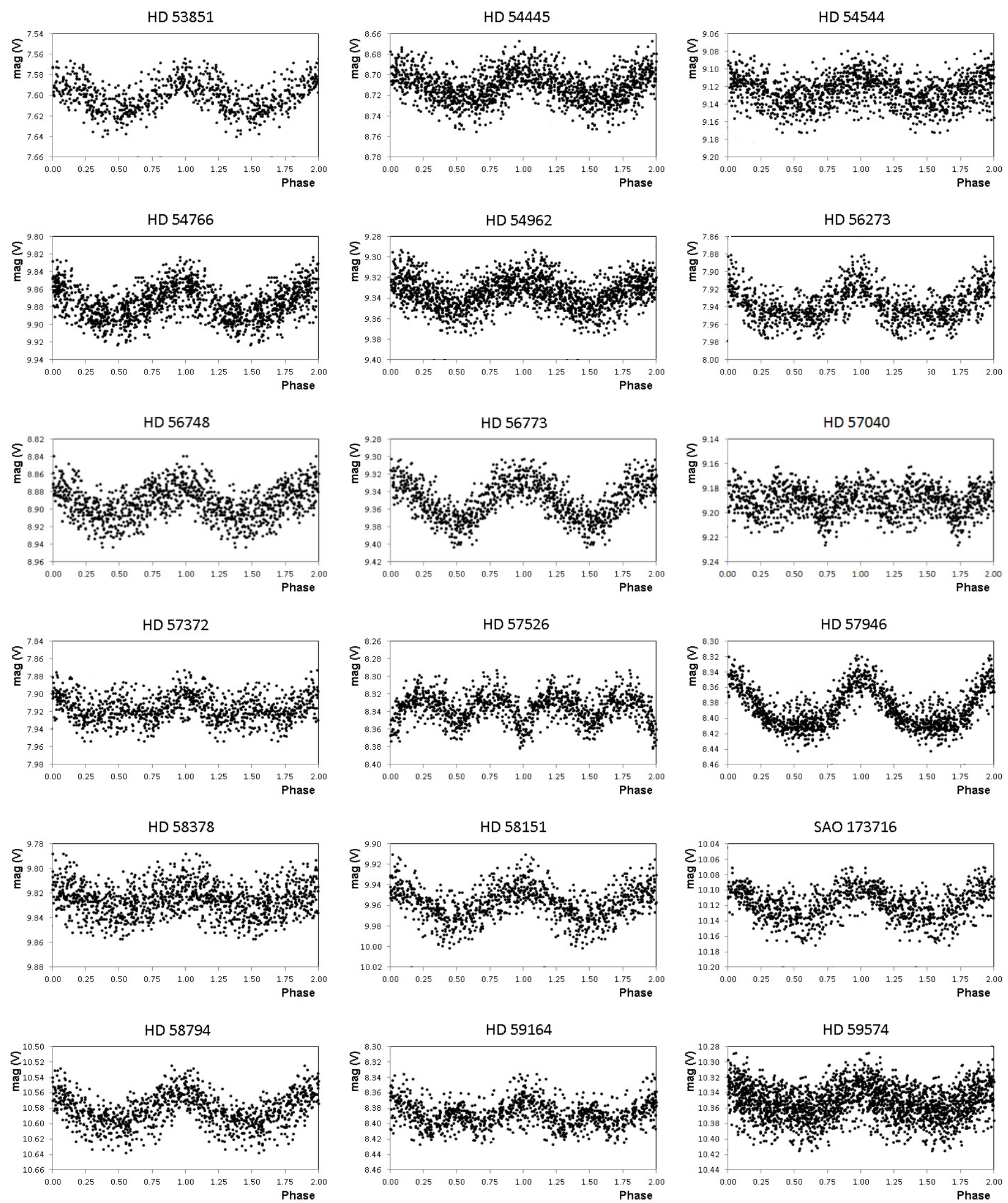

Fig. C.1. continued. 

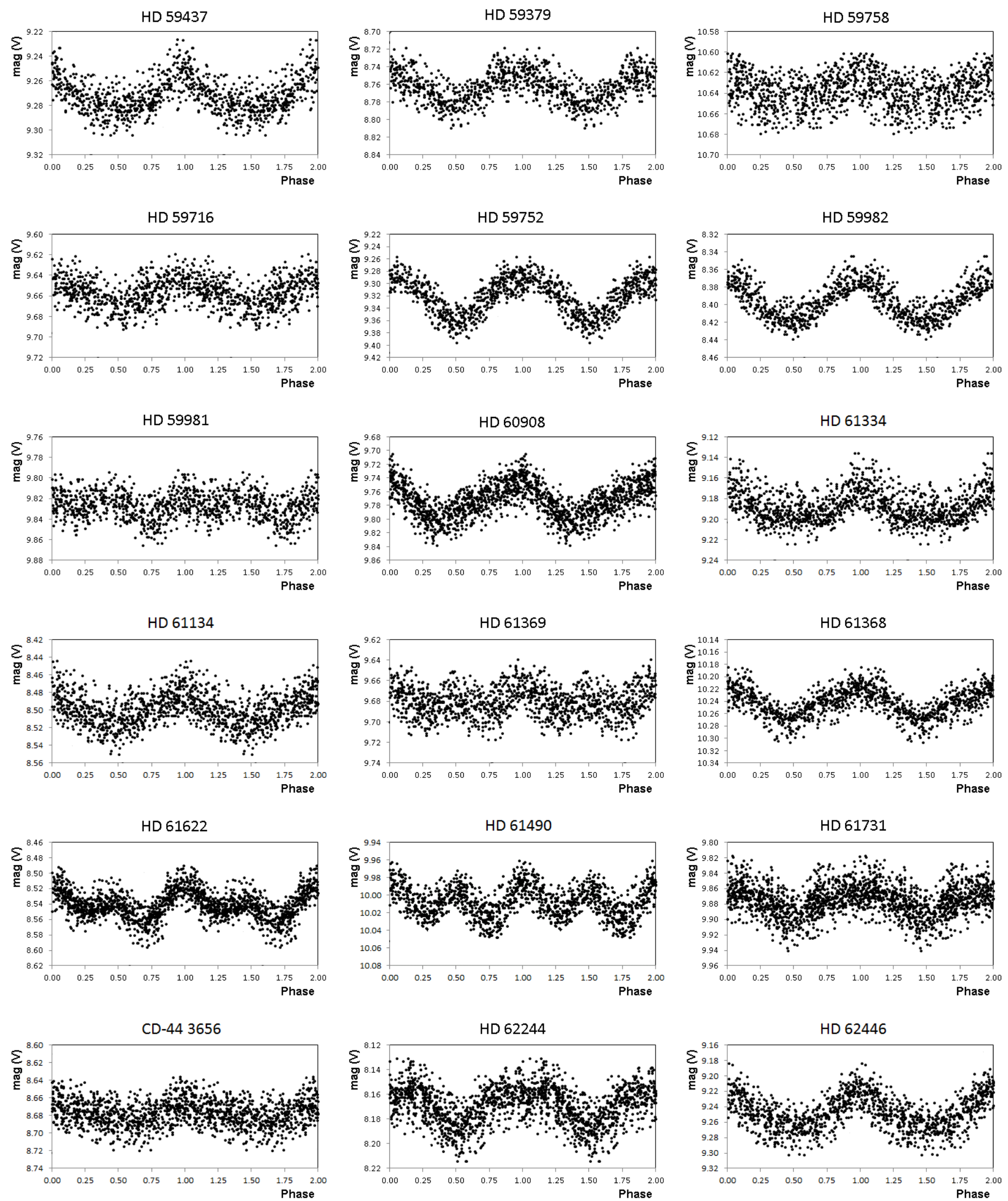

Fig. C.1. continued. 

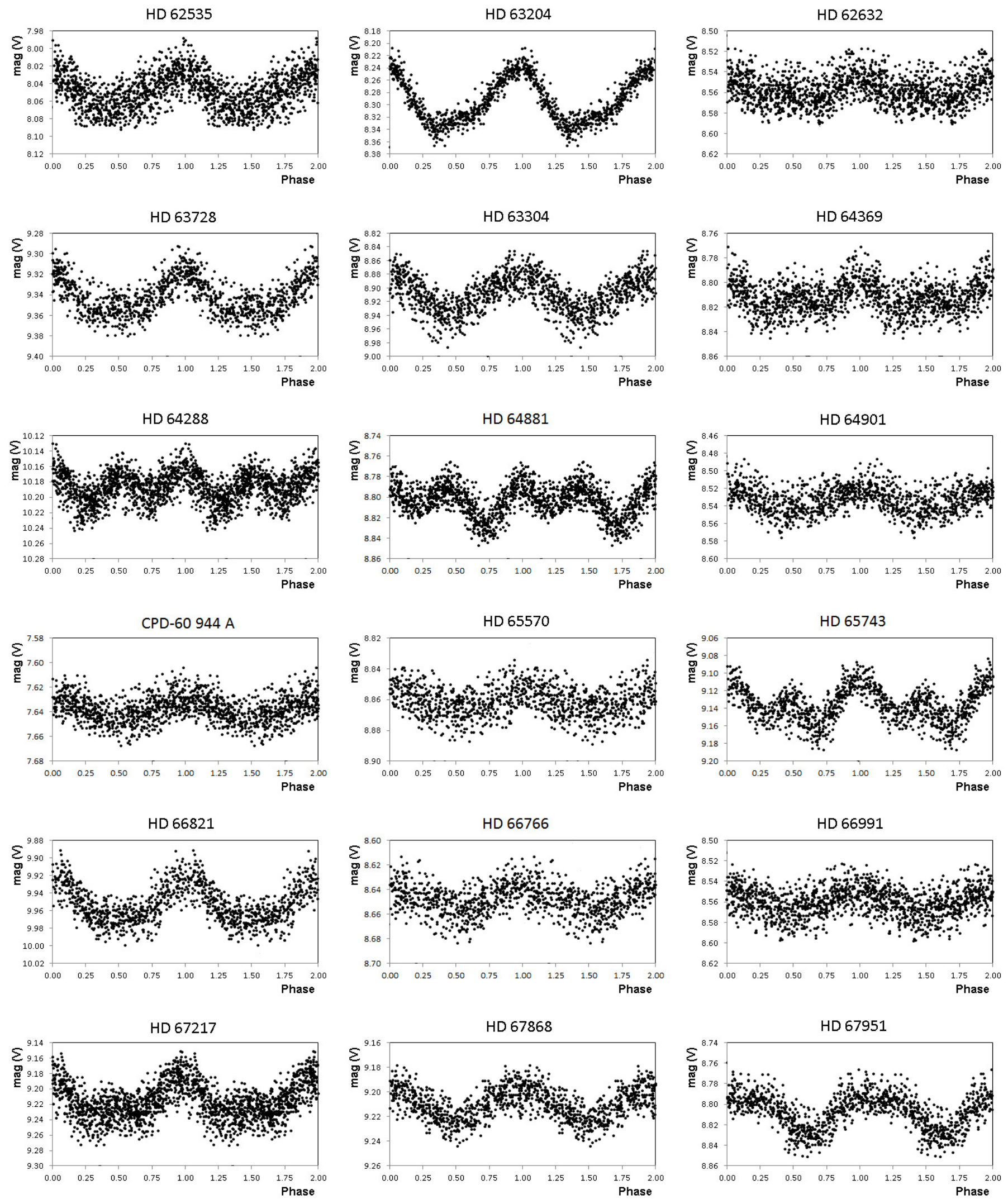

Fig. C.1. continued. 

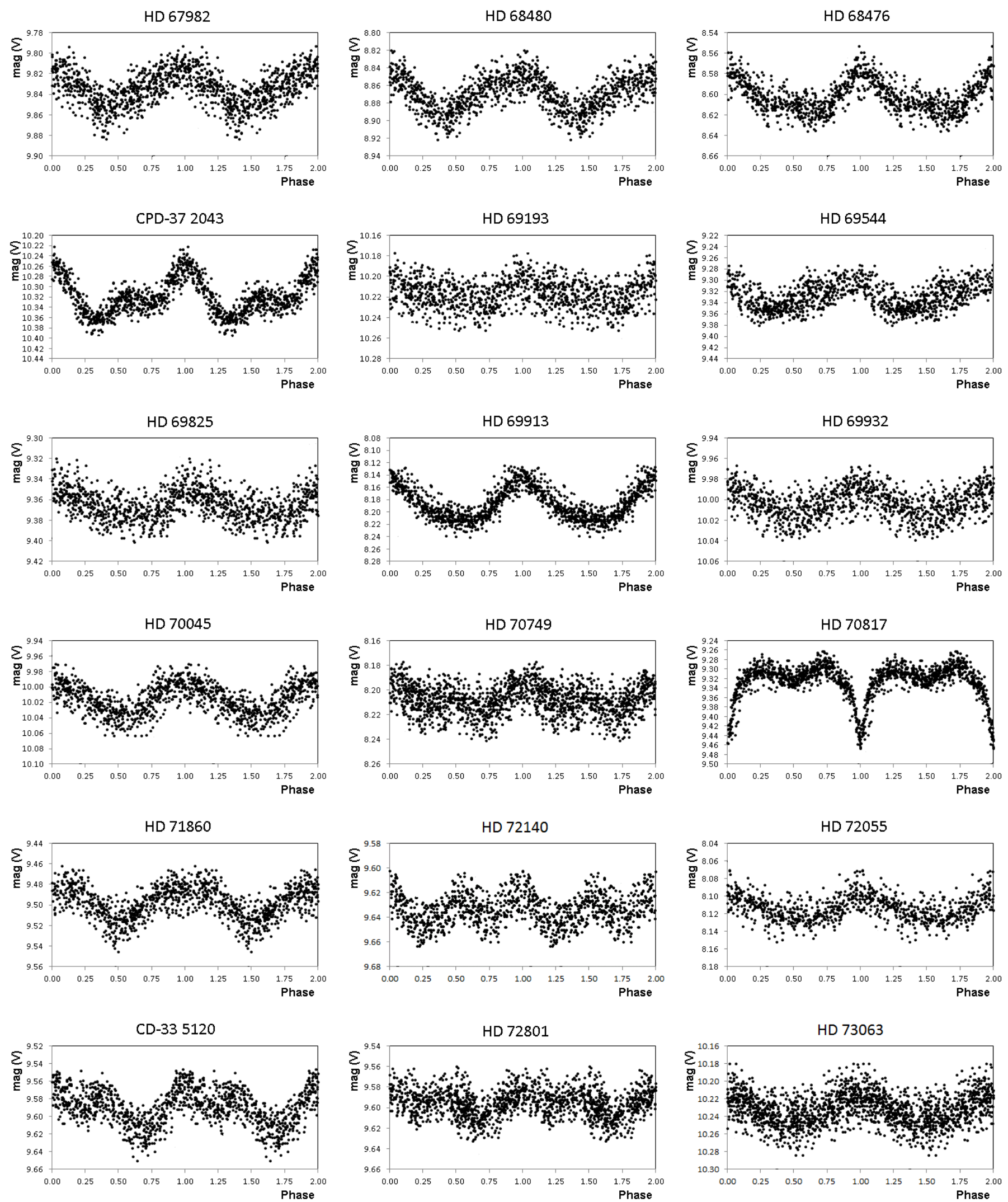

Fig. C.1. continued. 

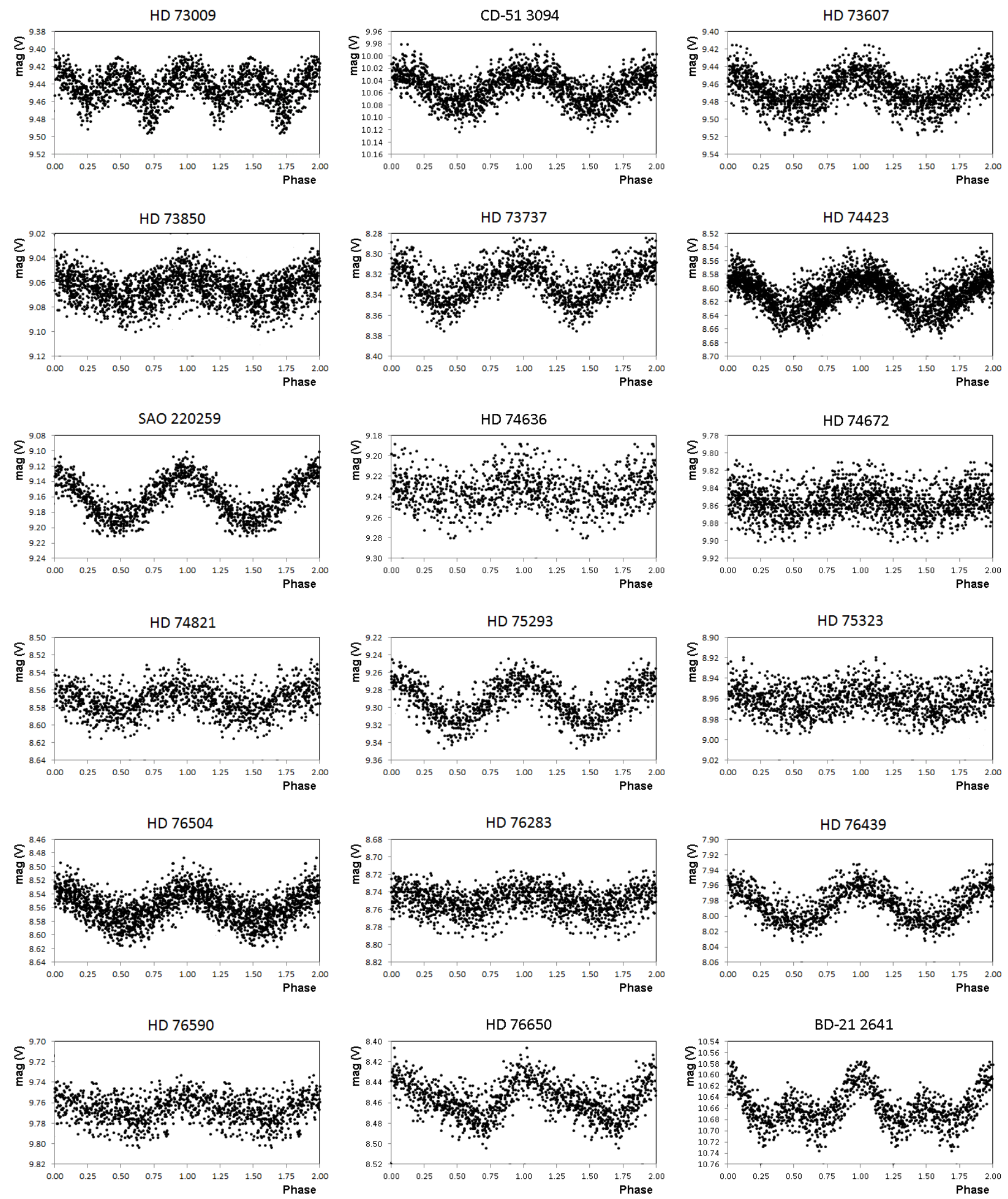

Fig. C.1. continued. 
K. Bernhard et al.: A search for photometric variability in mCP stars using ASAS-3 data
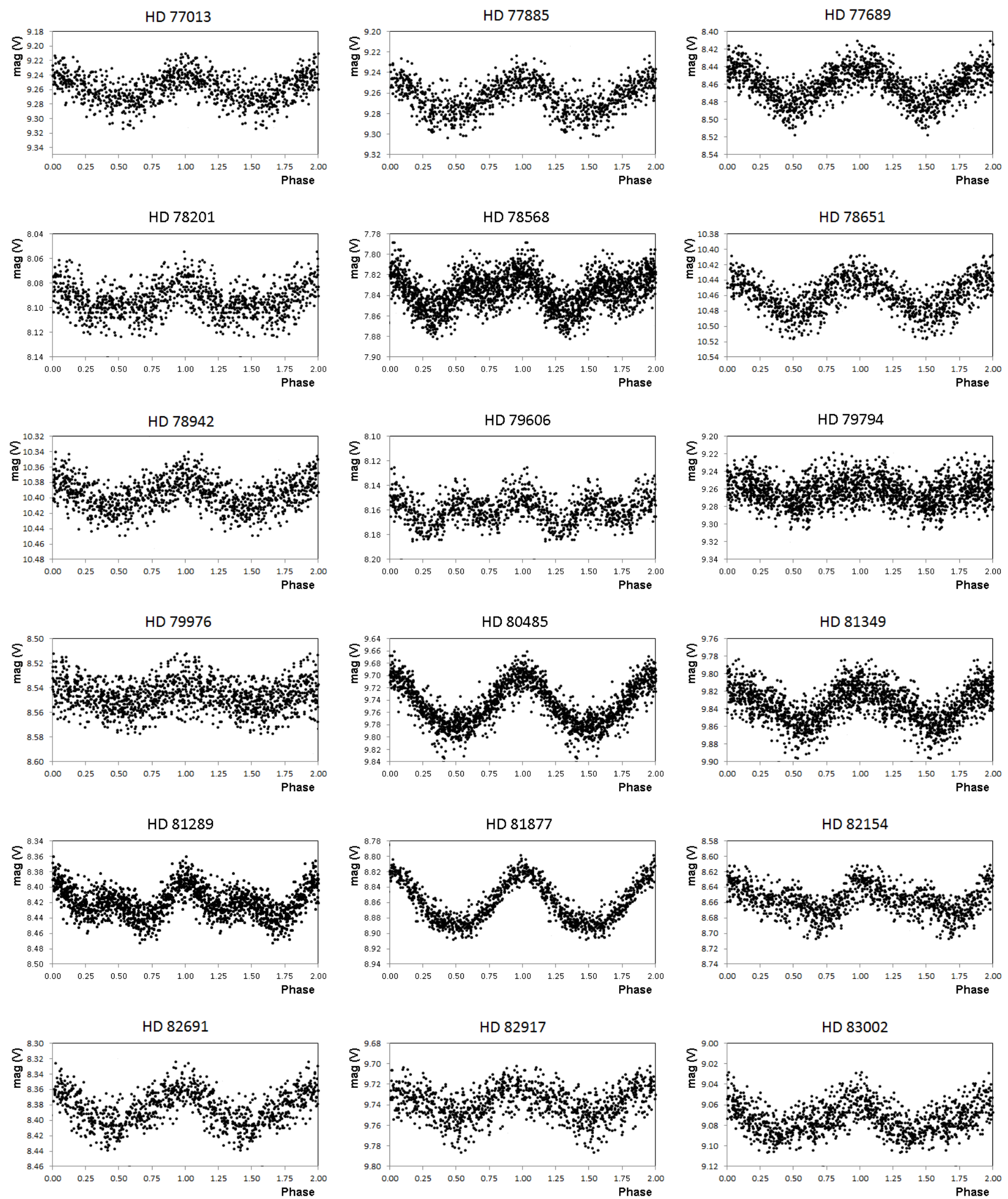

Fig. C.1. continued. 

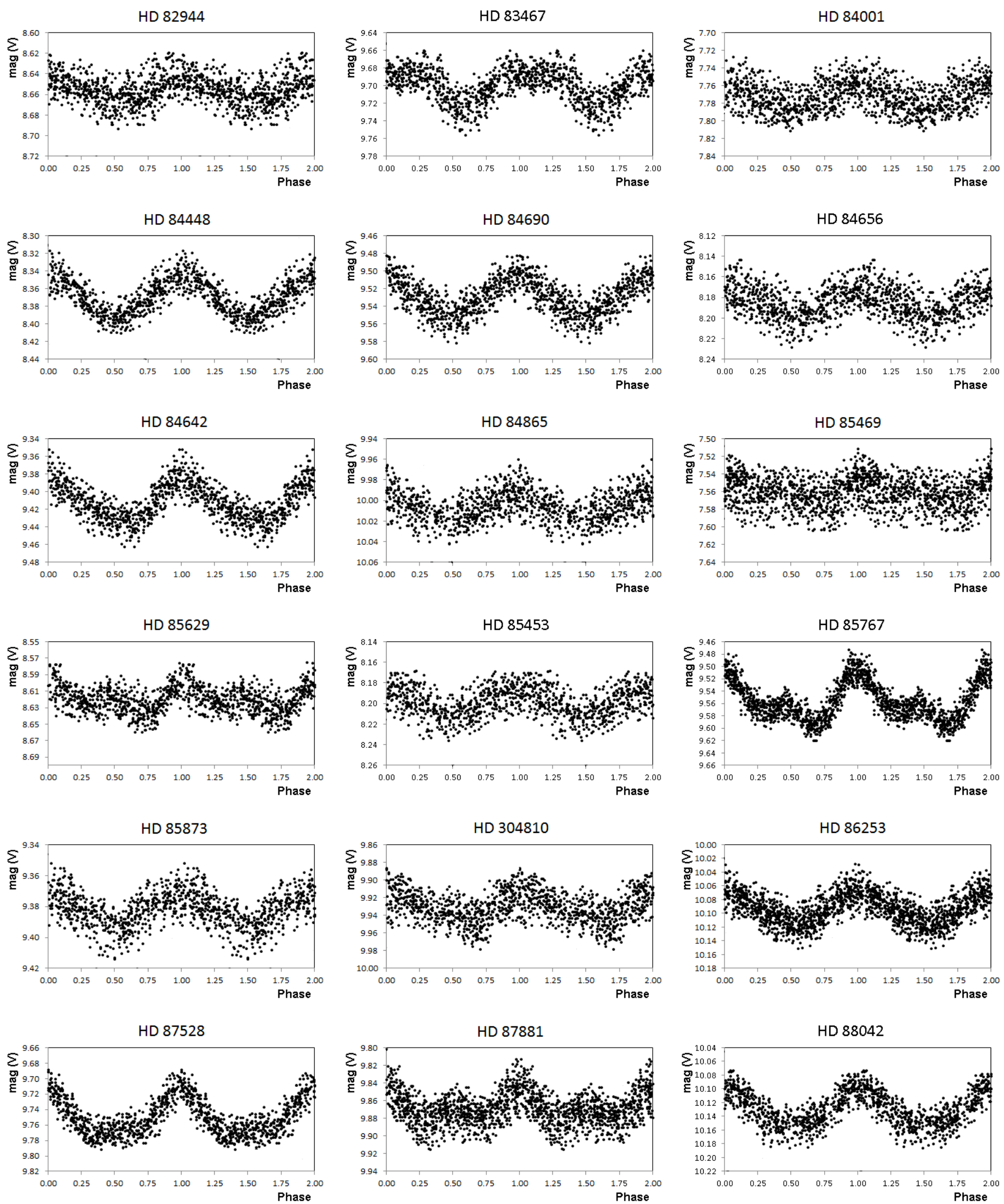

Fig. C.1. continued. 



Fig. C.1. continued. 

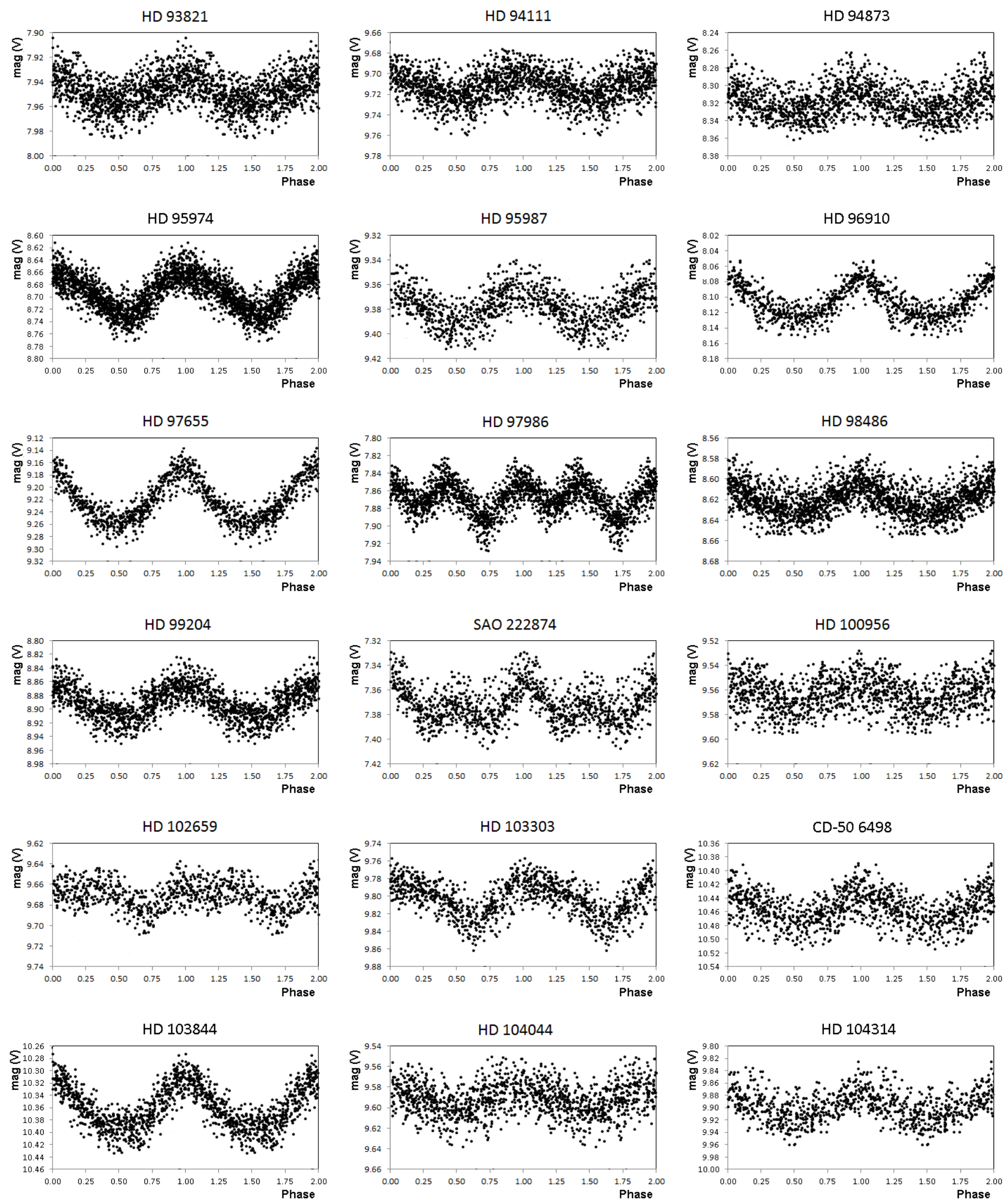

Fig. C.1. continued. 

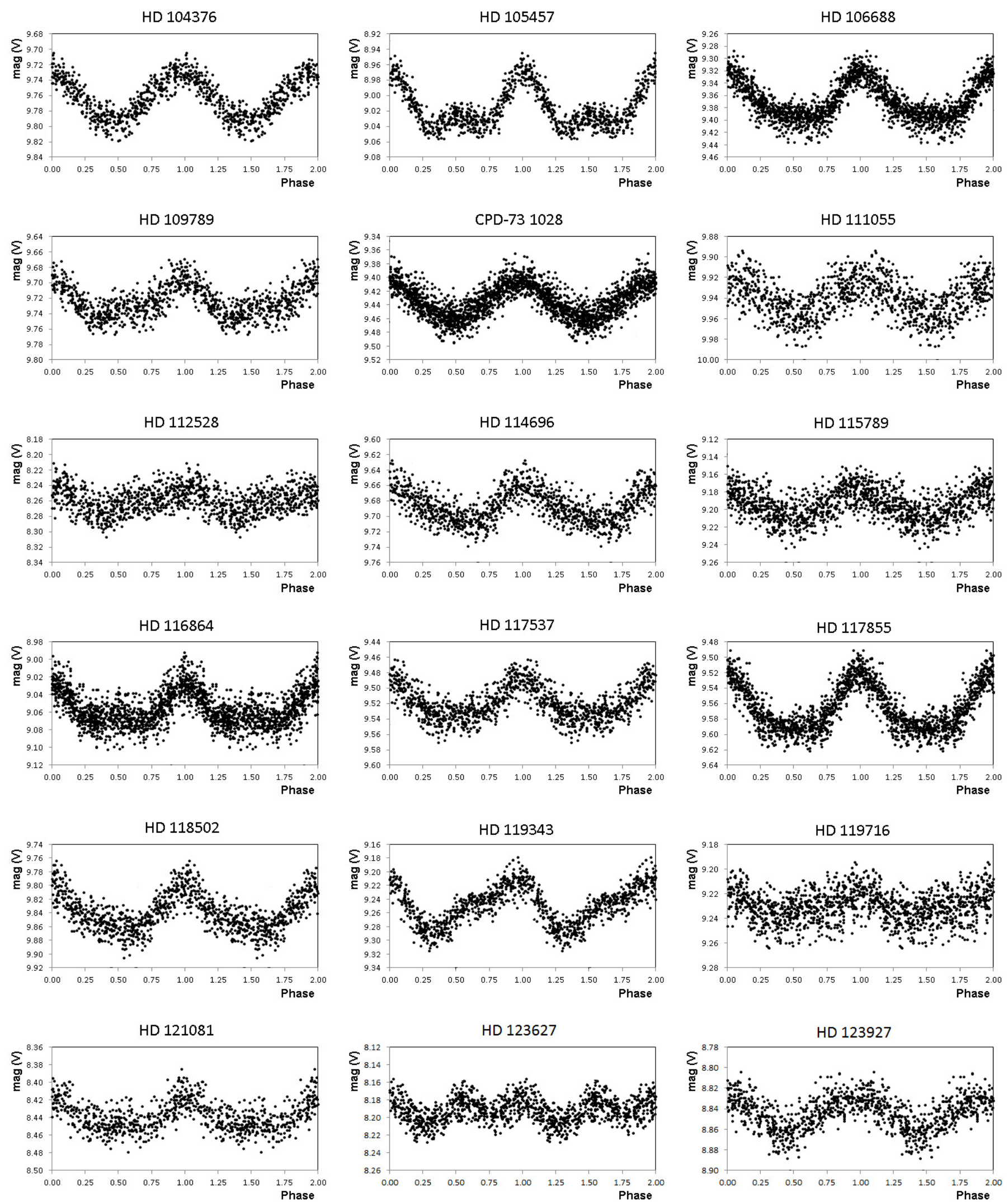

Fig. C.1. continued. 

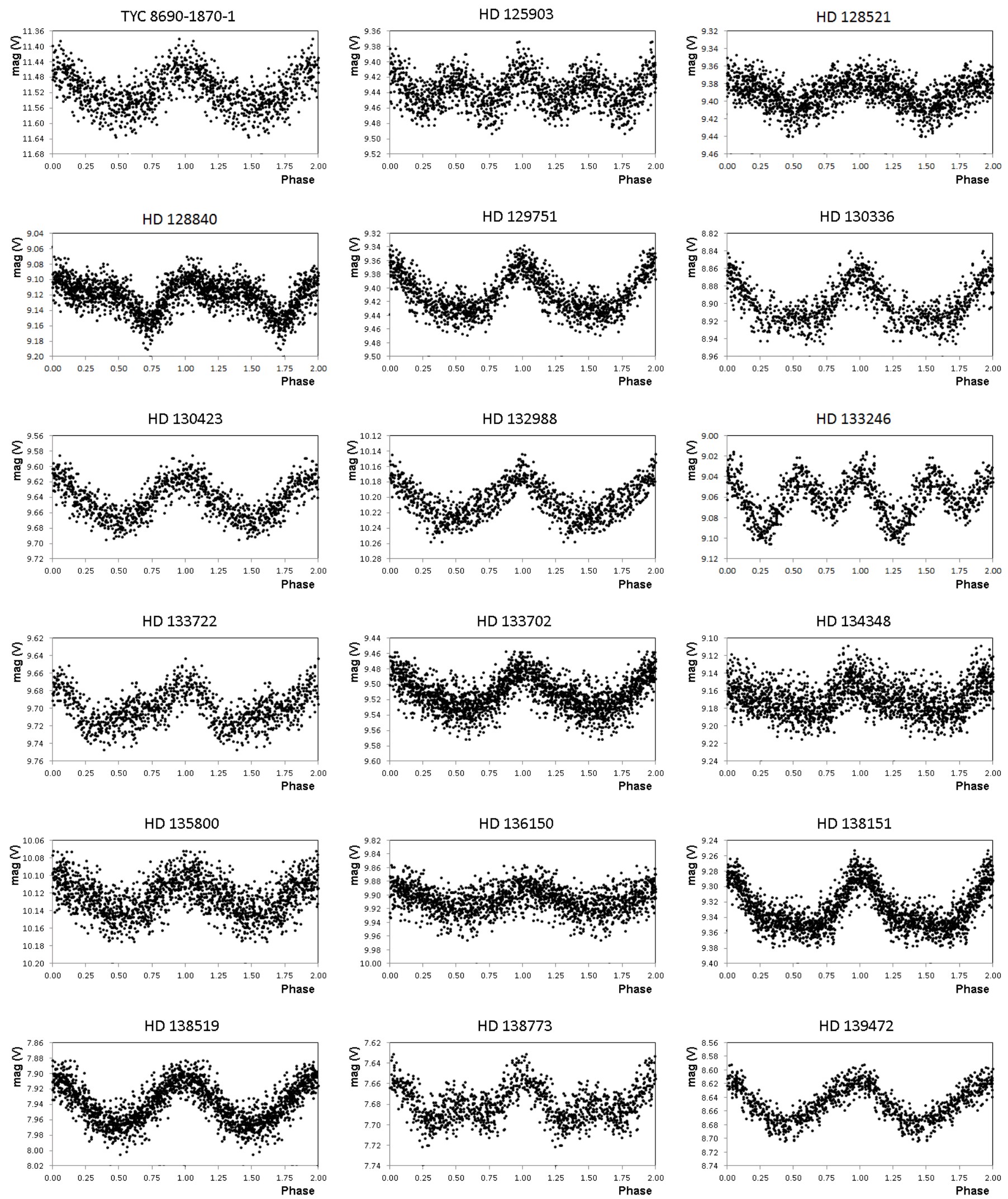

Fig. C.1. continued. 



Fig. C.1. continued. 



Fig. C.1. continued. 

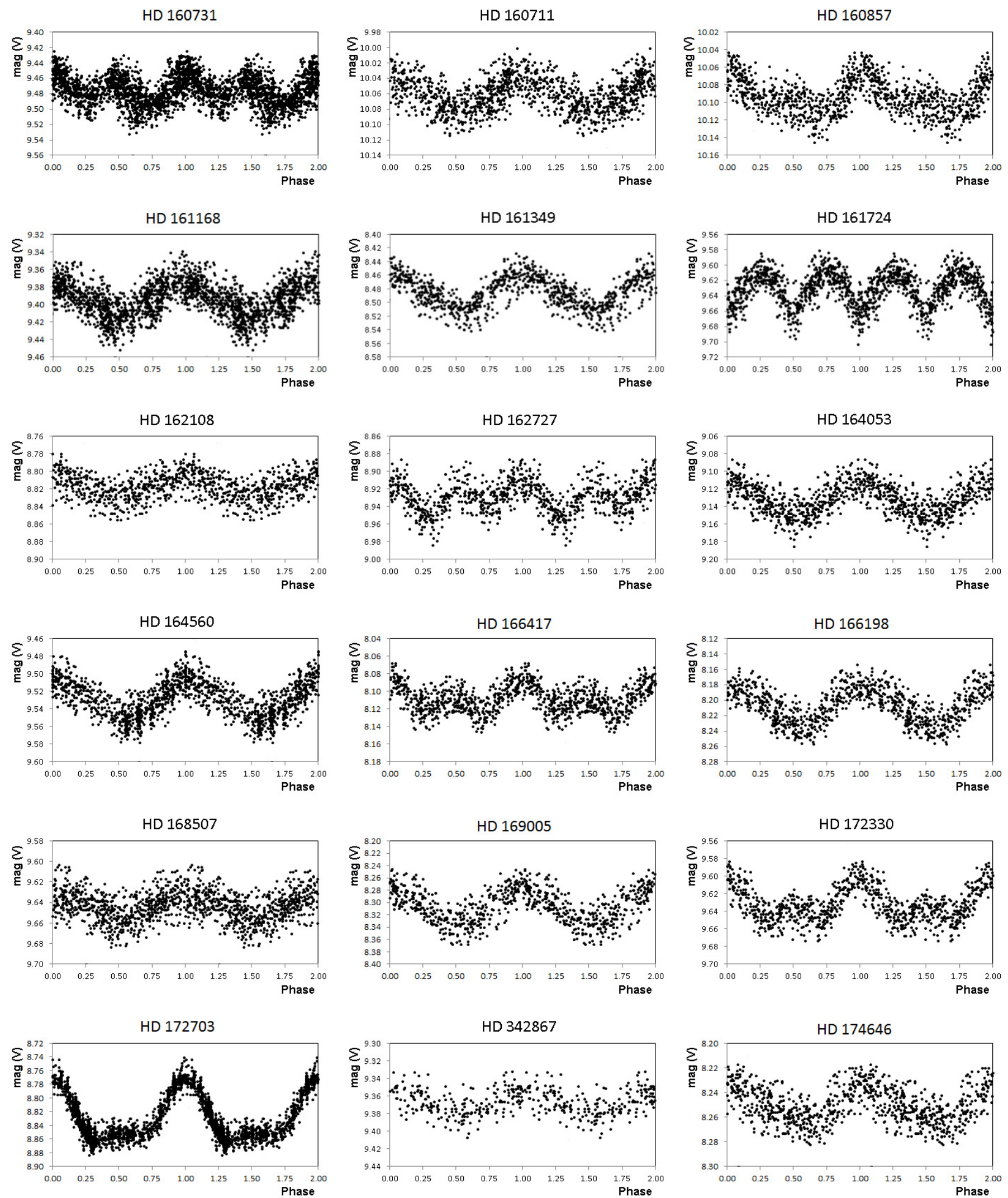

Fig. C.1. continued. 

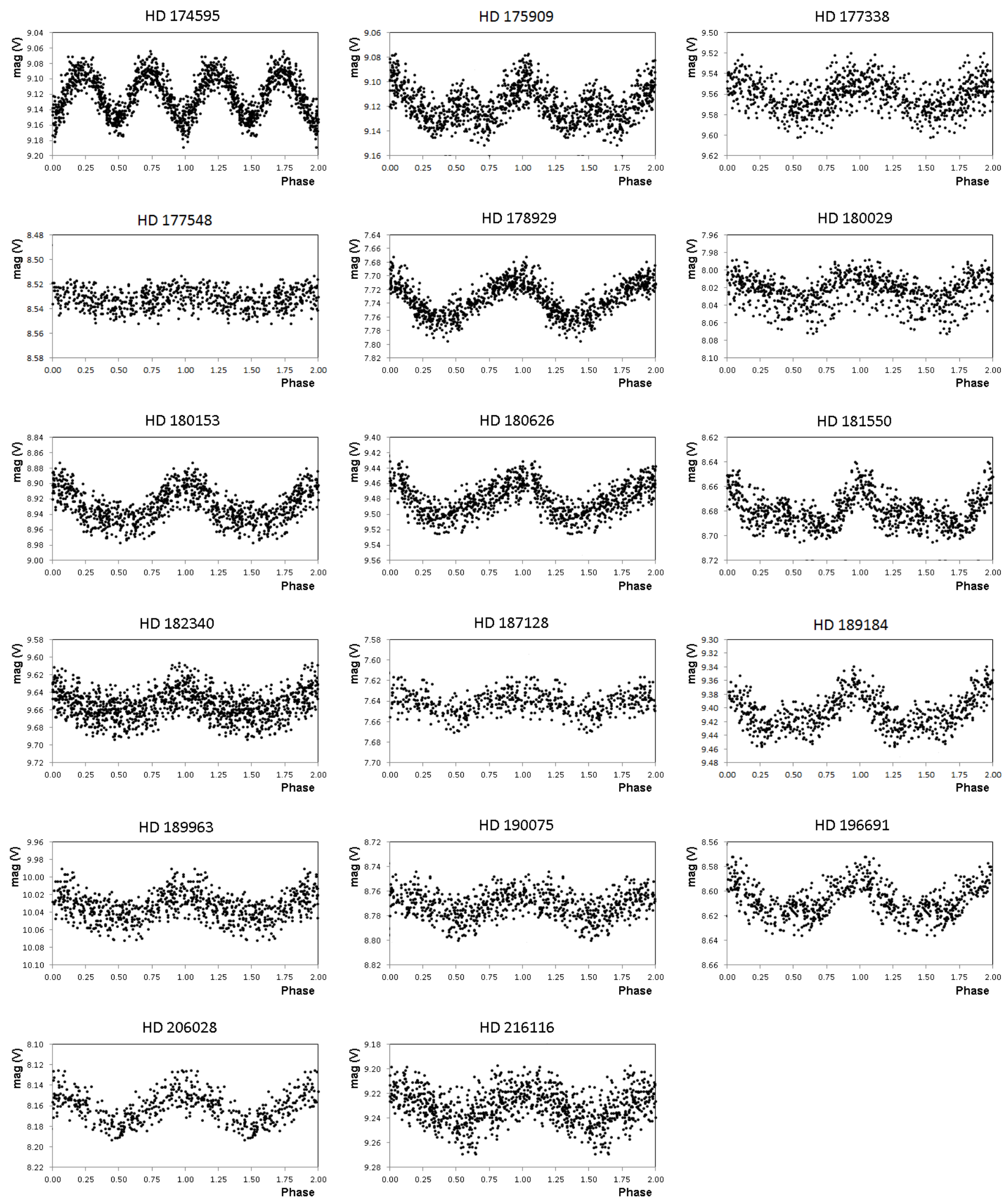

Fig. C.1. continued. 